\title{
Modulation of ochratoxins A-induced genotoxicity in Phaseolus vulgaris by multi-walled carbon nanotubes evaluated by phenotypic, cellular ultrastructure, and nuclear DNA bioassays
}

\author{
E. Abdelhaliem ${ }^{1}$ and H. Al-Otaibi ${ }^{2}$ \\ ${ }^{1}$ Plant Cytogenetic and Molecular Genetic, Botany and Microbiology \\ Department, Faculty of Science, Zagazig University, Sharkia, Egypt \\ ${ }^{2}$ Biology Department, Faculty of Science, Princess Nourah Bint \\ Abdulrahman University, Riyadh, Saudi Arabia \\ Corresponding author: E. Abdelhaliem \\ E-mail: ekram.esa@gmail.com
}

Genet. Mol. Res. 19 (1): gmr18509

Received October 21, 2019

Accepted January 11, 2020

Published January 25, 2020

DOI http://dx.doi.org/10.4238/gmr18509

\begin{abstract}
Recently, carbon nanotubes (CNTs) are gaining attention in the field of agriculture as advanced approaches to minimize toxicity of mycotoxins for crop plants. We examined whether MWCNTs can be used to alleviate genotoxicity and DNA damage induced by ochratoxin A (OTA) in the common bean (Phaseolus vulgaris) by comparing the action of three OTA doses, prior and post-adsorption of OTA on the surface of MWCNTs. The phenotypic parameters, ultrastructure of chloroplasts and nuclei using transmission electron microscopy, and status of nuclear DNA (nDNA) using flow cytometry, comet assay and random amplified polymorphic DNA (RAPD) were used as bioassays. Exposure time was 48 hours. The most effective MWCNT dose (optimal) was $50 \mu \mathrm{g} / \mathrm{mL}$; it enhanced the phenotypic parameters (seed germination and seedling growth, tolerance, and vigor indices), induced unexpected modification of size, shape, external and internal ultrastructure of chloroplasts and nuclei, increased the content of nDNA and genome size, reduced the extent of nDNA damage, and produced a larger number of amplified DNA products and new DNA bands more than the control. Lower and higher MWCNT doses had
\end{abstract}


reductions in these parameters. On the other hand, increases in doses in OTA treatments induced major toxicity in the common bean, leading to strong reductions in all parameters of the bioassays. The MWCNTs served as an adsorbent for OTA and led to alleviation of its toxicity. We conclude that optimal and adsorbent MWCNTs dose could be used as nanocarbon-fertilizer and nanocarbon-mycotoxin to protect crop plants in order to increase crop quality and productivity.

Key words: MWCNTs; OTA; Adsorption process; Cellular ultrastructure; RAPD-PCR; Comet assay and flow cytometry; Phaseolus vulgaris

\section{INTRODUCTION}

It Economically important crops are facing several challenges under increasing risk of mycotoxins, especially ochratoxins. Ochratoxins are a hazardous group of mycotoxins produced as secondary metabolites by several toxigenic fungi species such as Aspergillus ochraceus and Penicillium viridicatum that contaminate many types of economic crop plant products throughout the food chain which is a global problem (Pereira et al., 2014). Ochratoxins are dangerous, and the most prevalent toxin is ochratoxin A (OTA), which is one of the most abundant food-contaminating mycotoxins in the world and contaminates a variety of living economic crops and their products causing human illnesses and nutritional and economic losses of agricultural commodities in many zones of the world due to the accumulation of OTA in the food chain leading to alteration of the germination quality of these seeds (Ismaiel et al., 2015). They reported that OTA phytotoxicity ranging from significant inhibition in seed germination and seedling growth parameters, induction of necrotic lesions formation in leaves of various plants to cell death in other plants. Moreover, OTA is the only one of major mutagenic and genotoxic significance due to its production of free radicals and reactive oxygen species (ROS) that capable of carboxylation of proteins and oxidative DNA damage through a variety of oxidative pathways that lead to changes in plant growth, development, productivity, and reduction in the cellular antioxidant defense of crop plants (Pfohl-Leszkowicz and Manderville, 2012).

Taking the above into account, reduction of phytotoxicity levels of OTA is of great importance for many environmental, health and economic considerations. Several strategies have been developed to prevent the risk of OTA-phytotoxicity through conventional methods such as physicochemical and biological detoxification methods. These methods have not been optimal, because they may change the organoleptic characteristics and nutritional values of food (Madrigal-Santillán et al., 2010). One of alternative approach to neutralize the adverse effect of mycotoxins is selection and application of strong adsorbent materials for binding OTA toxicity in their aqueous solutions within few minutes of application and thereby decreasing their toxicity and bioavailability levels (Puzyr et al., 2007).

Fortunately, the advent of the carbon nanotubes (CNTs) as strong sorbent agent have brought a lot of hope for protection of economical crop plants from toxicity of hazardous organic and inorganic pollutants, heavy metals and mycotoxins from their aqueous solutions due to their large specific surface area for neutralizing or modulating these toxicities by altering the behaviour and the toxicity of these pollutants (Ihsanullah et 
al., 2015; Sadegh et al., 2015; Ma and Agarw, 2016). In this respect, Jang and Hwang (2018) reported that CNTs have a very strong sorption affinity for various genotoxic environmental pollutions; therefore, they may also influence the toxic effects of other toxic contaminants.

CNTs are cylindrical structures and can further be categorized into single-wall (SWCNTs) and multi-wall carbon nanotubes (MWCNTs) depending on the number of concentric layers of rolled graphene sheets. MWCNTs are the most interesting carbon-based nanomaterials due to their unique nanostructures and extraordinary properties that ranging from high electrical conductivity and large and reactive area to significant thermal stability (Fathi et al., 2017). The study of Horky et al. (2018) reported that CNTs especially MWCNTs have a great potential and binding activity properties to become a good sorbent for mycotoxin to reduce their toxicity on agricultural products. Nevertheless, their good adsorption capacity is well utilized in solid phase extraction protocols mainly for mycotoxins. The heightened attention in the strong adsorption capacity of MWCNTs derived predominantly from their unique surface morphologies such as unique tubular, highly porosity, hollow structure, excellent stability and large specific surface per weight, colloidal stability as well as their fast adsorption rate and strong affinity to a wide variety of toxic substances and the strong interaction between MWCNTs and toxic molecules (Ihsanullah et al., 2015; Ma and Agarw, 2016). Moreover, Ma and Agarwal (2016) observed that the efficacy of the adsorption process is affected by the physicochemical characteristics of both the adsorbent (MWCNTs) and the adsorbate (toxic substance). On the other hand, the study of Jiang et al. (2018) established a rapid, simple, sensitive and reliable procedure on the basis of one-step SPE cleanup using MWCNTs as absorbents followed by UPLCMS/MS analysis for simultaneous analysis of 21 mycotoxins, including nine trichothecenes, zearalenone (ZEN) and its derivatives, four aflatoxins, and two ochratoxins, in corn and wheat.

MWCNTs have recently gained interest due to their possible applications in agriculture field and plant science as promotor and regulator for seed germination and plant growth (Martínez-Ballesta et al., 2016; Zaytseva and Neumann, 2016; Fathi et al., 2017) because they consist of many hollow cylinders of carbon atoms inside one another and have a large surface area, which makes them potentially useful in extremely small-scale biological and agriculture applications. Several potential application of MWCNTs on many economic plants were found to have regulator and stimulator impact on seed germination and plant growth parameters as well as vegetative biomass of seedlings at different stages of development, depending on the model plant species and their growth stages as well as the size of applied CNTs, dose, solubility, exposure conditions, and its dispersion state (Khodakovskaya et al., 2012; Mastronardi et al., 2015; Yang et al., 2017; Lahiani et al., 2018). Additionally, MWCNTs have been observed as super fertilizers and fertilizer synergists, leading to increasing crop yield (Khodakovskaya et al., 2013). MWCNTs are also used as delivery systems for agrochemicals to reduce their amount and increase their use efficiency (Zaytseva and Neumann, 2016) and to activate constituents of pesticides, herbicides, and insecticides for plant protection and as antifungal and antimicrobial agents (Zaytseva and Neumann, 2016; Mohamed et al., 2018). On the other hand, phytotoxicity and inhibitory effects of MWCNTs on germination, cell cultures, and genetic effects has been reported by some researchers at higher concentrations (Tiwari et al., 2014; Kaphle et al., 2017). Additionally, MWCNTs can inhibit seedling growth and change morphological, 
physiological, biochemical, molecular, and genetic parameters in plants (Gopalakrishnan Nair, 2018).

Now, plant bioassays are well-established systems and are used for screening and monitoring environmental chemicals. Economic crop plant common bean (Phaseolus vulgaris, Fabaceae) is one of the most important dietary legumes and a vital source of nutrition worldwide as well as very important to both the developed and developing world as a dietary protein (Kalavacharla et al., 2011). It is frequently used as a model plant and as a biosensor for the identification of the mechanism of toxic substances and for providing standardized methods for cellular, physiological, biochemical and molecular analyses of toxicology (Kalavacharla et al., 2011).

The value of plant systems for monitoring and screening genotoxicity can be improved by: greater understanding of the biological consequences and molecular mechanisms of positive (stimulatory) and negative (toxicant) of any genotoxic agent as well as plant cell processes ranging from phenotypic, cellular ultrastructural and DNA-based molecular levels (Talebi, 2018). This is due to any variation in DNA sequence can cause variation in gene expression, which influences quantitative phenotypic variation in plants as well as structure and function of any cellular organelle inside plant. Nevertheless, using phenotypic analyses only may be difficult to assess effect of any treatment on crop plants without supporting data from their cellular biology and DNA-based molecular analyses.

The phenotypic parameters are extremely important for seed germination and growth and development of all plants and each environmental agent that changes their morphology has positive/negative effects on plants. So, plants respond to toxic stress exposure injury by changing their morphology or growth rate (Talebi, 2018). The phenotypic parameters can be used as a reliable indicator for specific genes that activate the synthesis of some proteins such as water channel proteins (aquaporins) that facilitate water uptake and essential for cell division, cell wall extension, plasma membrane formation, and promotion and transport of water (aquaporins) that lead to stimulation of seed germination and plant growth or versa (Schmidt and Kunkowska, 2016).

Flow cytometry (FCM) is multiparametric and a rapid technique and has the ability to detect minute alterations in nuclear DNA (nDNA) content and genome sizes that induced by environmental genotoxic pollutions in addition to evaluate the chromosomal broken and DNA damages, cell cycle dynamics and polyploidization in exposed plants (Monteiro et al., 2010)

Plant-based molecular genetic bioassay-comet assay also called, Single Cell Gel Electrophoresis assay (SCGE) is a powerful genetic bioassay and most advanced technique for the detection of DNA damage and DNA repair in the plant sciences in recent years. Comet assay can determine DNA strand breaks such as (oxidative DNA base damage, and DNA-DNA/DNA-protein cross-linking, DNA adducts) at the cell level (Dikilitas et al., 2009). It is considered one of the most popular tests of genotoxicity and DNA damage detection induced by mycotoxins, phytocompounds, heavy metals, nanoparticles or contaminated complex matrices due to its simplicity, sensitivity, economical use, speed, and the small number of cells (Santos et al., 2015). The study of Ghosh et al. (2015) was the only study that demonstrated a correlation between DNA damage and dose of multi-walled carbon nanotubes in Allium cepa, supporting the genotoxic potential of this type of nanomaterials at higher doses. 
For genotoxicity measurement, it is important to use certain bioassays that indicate a wide range of DNA alternations, mutations, and other DNA damages such as RandomLy amplified polymorphic DNA-polymerase chain reaction (RAPD-PCR) and molecular cytogenetic assays such as comet assays. RAPD-PCR are widely applicable techniques used as a tool to detect alterations at the DNA sequence level based on DNA intensity and gain new bands or loss of normal bands of DNA bands following toxicant exposures compared with DNA fingerprints of untreated samples (Atienzar and Jha, 2006; Kekec et al., 2010). Reports using combination of RAPD, comet assay, and flow cytometry bioassays for reliably assessment of the effect of MWCNTs and OTA treatments on plants are still lacking.

Considering the above, the present study aimed to : 1) evaluate influences of Multiwalled carbon nanotubes as well as phytotoxicity of ochratoxin A on common bean seeds 2) test the efficiency of the possible stimulatory dose of MWCNTs as good adsorbent for binding OTA toxicity in their aqueous solutions to neutralize and alleviate their phytotoxicity on economic crops 3) applicant MWCNTs in agriculture for protection of economic crops from ochratoxin A and increasing the agricultural production in future.

\section{MATERIAL AND METHODS}

\section{Test plant and experimental design}

Seeds of common bean (Phaseolus vulgaris cv. super strike) were obtained from the King Saud University, College of Food Science and Agriculture, Department of Plant Production, Riyadh. Saudi Arabia and used as the plant material in this study. Fresh and healthy uniformity size seeds were cleaned, and surface sterilized in a $1 \% \mathrm{v} / \mathrm{v}$ solution of sodium hypochlorite by gentle magnetic stirring for $10 \mathrm{~min}$, then rinsed three times with deionized water and aerated continuously for $12 \mathrm{~h}$. Seeds divided into four groups. The first group of seeds was untreated control (without any treatments). The second group was treated with MWCNTs doses, the third group with OTA doses, and the fourth group was treated with OTA adsorbate solutions after sorption process. Design of experiment was listed in Table 1.

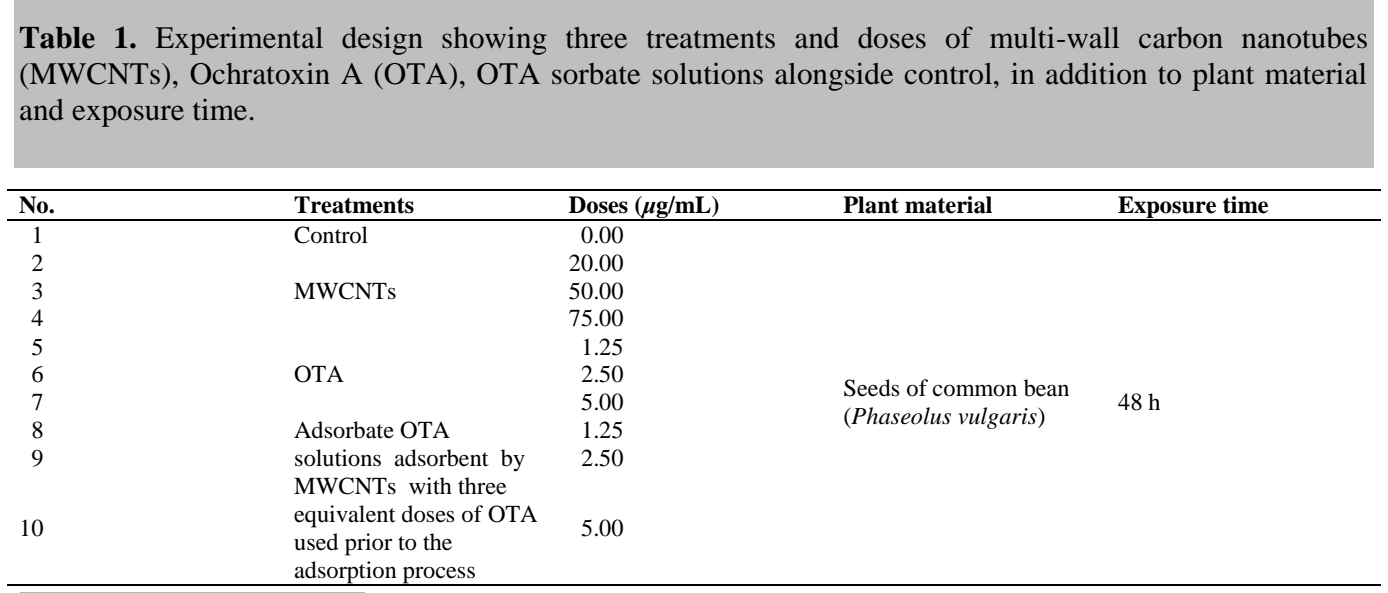




\section{Ochratoxin A and preparation of OTA doses}

Pure, crystalline Aspergillus ochraceus Ochratoxin A (OTA) solutions were purchased from (Sigma Chemical Co, St Louis, MO, USA). Selection and preparation of OTA doses were in the range of doses reported in the study of Lerda et al. (2010). The experimental treatments included three OTA doses $(1.25,2.50,5.00 \mu \mathrm{g} / \mathrm{mL})$. Distilled water was used as an untreated control (without OTA).

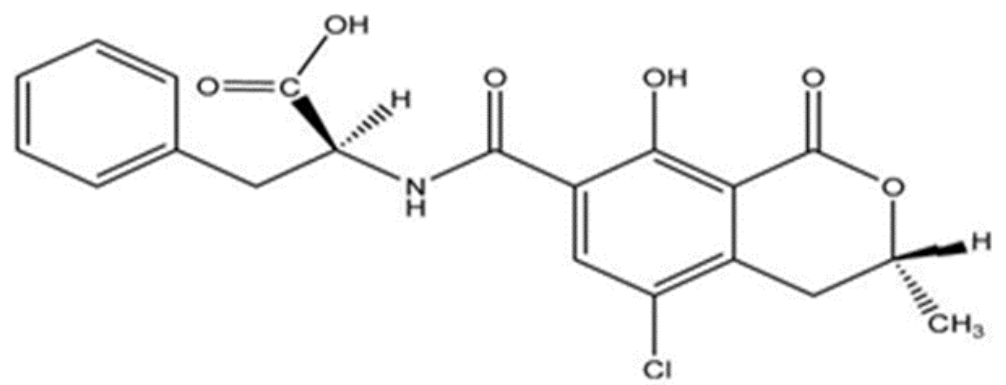

Figure 1. Chemical formula of ochratoxin $\mathrm{A}$ is $\left(\mathrm{C}_{20} \mathrm{H}_{18} \mathrm{ClNO}_{6}\right)$ and its chemical structure, taken from (El Khoury and Atoui, 2010).

\section{MWCNTs and preparation of MWCNT suspensions}

The black powder of MWCNTs having (purity: $98 \%$, OD: 8-15 nm, Length: 10-30 $\mu \mathrm{m}$, Size: $0.1-0.5 \mu \mathrm{m}$ and Surface area $90-350 \mathrm{~m}^{2} / \mathrm{g}$ ) was purchased from MK Nano (division of M K Impex Corp.), Canada and used as received for this study. To increase the water solubility of MWCNTs powder, we soaked it in a mixture of $\mathrm{H}_{2} \mathrm{SO}_{4}$ and $\mathrm{HNO}_{3}(3: 2)$ for $24 \mathrm{~h}$ as described in the study of Wang et al. (2012). MWCNTs black mass was washed with distilled water several times and evaporated under boiling water bath for removing all traces of acids and till it became neutralized. After that, the completely dried black powder of MWCNTs was suspended directly in deionized water and dispersed using mechanical stirrer, followed by sonication on ice by ultrasonic vibration at $100 \mathrm{~W}, 30 \mathrm{KHz}$ (UP100H Ultrasonic processor, Hielscher Ultrasound Technology, Germany), for $30 \mathrm{~min}$ and vigorous vortexed to obtain homogeneous suspensions $(5 \mathrm{~min})$ used for the experiment. A batch hydroponic experiment in triplicate was conducted to determine the positive and negative effects of three MWCNTs doses $(20,50$, and $75 \mu \mathrm{g} / \mathrm{mL})$ on the seed germination and growth seedlings of $P$. vulgaris. The selected doses were in the range of doses reported in other study (Wang et al., 2012) while distilled water (DI) without MWCNT was used as untreated sample (control).

\section{Characterization of MWCNTs suspension}

The suspension of multi-walled carbon nanotubes prepared in above section were used for TEM and SEM methods to study the morphology of MWCNTs. For Transmission electron microscopy (TEM, Hitachi H-7650, Japan) observation, one drop of the suspension was placed on 300 mesh copper grips, which was coated with holey carbon film and dehydrated at $40^{\circ} \mathrm{C}$. In case of scanning electron microscopy (Hitachi S-415A electron 
microscope at $25 \mathrm{kV}$ ) observation, the obtained solution was dropped on a silicon substrate slide and dried at $40^{\circ} \mathrm{C}$.

\section{Treatments of $\boldsymbol{P}$. vulgaris seeds and germination experiments}

Viable and healthy uniformity size common bean seeds were used in this study. Under the laboratory conditions, a completely randomized design with triplication was conducted to determine the effects of $48 \mathrm{~h}$ exposure of MWCNTs $(20,50$, and $75 \mu \mathrm{g} / \mathrm{mL})$ and OTA $(1.25,2.50,5.00 \mu \mathrm{g} / \mathrm{mL})$ doses on different phenotypic parameters of seed germination and seedling growth and ultrastructure of chloroplast and nuclei of $P$. vulgaris. Twenty surface-sterilized common bean seeds were placed on sterilized petri dishes and soaked in $30 \mathrm{~mL}$ of each dose of MWCNTs or OTA or OTA sorbate solutions alongside control samples. The solution level of each treatment was maintained to avoid changes in exposure dose. After $48 \mathrm{~h}$, all treated and untreated common bean seeds were washed three times with distilled water, set of them used for analyses by different bioassays while other set germinated on sterilized cotton wool saturated with distilled water placed in sterilized petri dishes which set in an incubator at $25^{\circ} \mathrm{C}$. Seeds were considered to be germinated when they exhibited a radical extension of $>2 \mathrm{~mm}$ long and plumule has just unfolded. Counts of germinated seeds were made for 48,72 and $96 \mathrm{~h}$ from emergence of radical following the International Seed Testing Association (ISTA) rules.

\section{Estimation of seed germination parameters}

The current study estimated the following parameters of seed germination that calculated, as given by (Tanveer et al., 2014): the final germination percentage (FGP),coefficient of velocity of germination (CVG) is an index for germination speed, means daily germination (MDG) is an index of daily germination rate, and the phytotoxicity of germinated seeds as per (Tanveer et al., 2010). These parameters were evaluated by count as the equations below:

\section{The final germination percentage (FGP):}

$$
\text { FGP }=\frac{\text { Number of germinated seeds after }(48,72,96) \text { Hours }}{\text { Total number of seeds }} \times 100
$$

\section{Means daily germination (MDG):}

$$
M D G=\frac{\mathrm{FGP}}{\mathrm{D}}
$$

Where FGP is final germination percent; D is day of experimental period.

\section{Coefficient of velocity of germination (CVG)}

$$
\mathrm{CVG}=\frac{\text { No.of Germinated seeds on day } 1}{1}+\cdots+\frac{\text { No.of germinated seeds on day } n}{n}
$$

Where $\mathrm{n}=$ number of days after sowing 


\section{The phytotoxicity for germinated seeds:}

$$
\% \text { of phytotoxicity }=\frac{\text { Radical length of control-Radical length of treated }}{\text { Radical length of control }} \times 100
$$

\section{Estimation of seedling growth parameters}

After all treatments, each replicate (corresponding to treated and untreated common bean seeds) was washed three times with distilled water and immediately transferred to sown in earthenware pots $(30 \mathrm{~cm}$ high $\times 20 \mathrm{~cm}$ diameter) containing soil obtained from topsoil in the field and grown in greenhouse for 40 days until reached seedling stage. Triplicates of 10 seedlings were randomLy sampled, and the following seedling growth parameters were recorded: mean lengths $(\mathrm{cm})$ of seedlings and the percentage of phytotoxicity of shoot and root of seedlings was calculated following the formula given by (Mishra and Choudhuri,1999). The mean of dry weight of seedlings (g) were also measured.

The tolerance index (TI) and seedling vigor indices (VI) I and II were computed based on (Vashisth and Nagarajan, 2010), respectively as shown in the following equations below:

$$
\begin{gathered}
\% \text { Phytotoxicity }=\frac{\text { Shoot or root length of control }- \text { Shoot or root length of treatment }}{\text { Shoot or root length of control }} \times 100 \\
\text { Tolerance index }(\mathrm{TI}) \%=\text { Root length of treatment } / \text { Root length of control } \times 100 \\
\text { Vigor index }(\mathrm{VI}) \mathrm{I}=\text { Seedling length }(\mathrm{cm}) \times \text { Germination }(\%) \\
\text { Vigor index }(\mathrm{Vi}) \mathrm{II}=\text { Seedling weight }(\mathrm{g}) \times \text { Germination }(\%)
\end{gathered}
$$

\section{Preparation of chloroplasts and nuclei for Transmission electron microscopy}

After plantation of treated and untreated common been seeds under field conditions for a period of 5 weeks, Fresh, green, and actively growing leaves which fully expanded were harvested and immediately prepared for examination of chloroplasts and nuclei ultrastructure using the Transmission Electron Microscopy (TEM) according to method used by the Electron Microscopic Unit, Central Laboratory, Faculty of Science, King Saud University as following: specimens for TEM analysis were obtained from the central part of healthy green leaf blades (second or third leaf) and were fixed in primary fixation of buffered Glutaraldehyde $2.5 \%$ over night in refrigerator, then wash by phosphate buffer $\mathrm{pH}$ 7.2 for $12 \mathrm{~h}$ at room temperature, followed by secondary fixation in buffered Osmium Tetroxide solution $1 \%$ over night in refrigerator. The specimens were rinsed and dehydrated in a graded series of ethanol concentrations and were embedded in resin mixture from SPI (SPI-Pon ${ }^{\mathrm{TM}}$ - Araldite ${ }^{\circledR}$ Epoxy Embedding Kit). Microtome sections were prepared in the Leica UC6 ultra microtome using Diatome diamond knives, the section thickness was between 70-80 nm and it was mounted on a copper grid with 300 mesh squares. Staining of specimens was carried out using aura's uranyl acetate and lead citrate. The specimens were then examined and photographed under TEM (JEOL - JEM-1400 series $120 \mathrm{kV}$ electron microscope) Unit, Central Laboratory, Faculty of Science, King Saud University using different amplifications. For each sample, 5-10 sections were examined. 


\section{DNA-based bioassays}

In this study, seeds were used instead of leaves in bioassays (flow cytometry, comet assay, and RAPD-PCR) to avoid the accumulation of staining inhibitors within leaves which significantly reduce DNA yield and quality (Sliwinska et al., 2005). Treated common bean seeds with MWCNTs, OTA, OTA adsorbate solutions for $48 \mathrm{~h}$ alongside control samples were used for analyses by flow cytometry, comet assay and RAPD as DNA bioassays.

\section{Flow cytometry}

Seeds were used for the estimation of DNA content and genome size by flow cytometry because the majority of its the embryo cells are arrested in the G0/G1 phase of the cell cycle (having a 2C DNA content) (Sliwinska et al., 2005; Sliwinska, 2006).

\section{Estimation of variation in nuclear DNA content and genome size}

The variations in nuclear DNA content and genome size of common bean nuclei were estimated using a simple and rapid protocol of Arumuganathan and Earle (1991) as described in the study of Abdelhaliem and Al-Shalawi, (2019) as following: Fifty mg of common bean seeds were chopped into $<0.5 \mathrm{~mm}$ pieces on ice using a sharp razor blade after adding $1 \mathrm{~mL}$ of solution A (14.3 mL $\mathrm{MgSO}_{4}$ buffer (ice-cold), $15 \mathrm{mg}$ dithiothreitol (Sigma, D-0632), $300 \mu \mathrm{L}$ fluorochrome stain, propidium iodide (PI) stock, and $375 \mu \mathrm{L}$ Triton X-100 stock) in plastic petri dishes. The pieces were then homogenized using a mortar for isolation of nuclei from treated and untreated seeds. The solution of homogenized nuclei was filtered through a nylon cloth $(50 \mu \mathrm{m}$ mesh size $)$, centrifuged at $15000 \mathrm{~g}$ for 15 to $20 \mathrm{~s}$ and finally the supernatant discarded. The pellet was resuspended in $200 \mu \mathrm{L}$ of solution B ( $3 \mathrm{~mL}$ Solution A, 7.5 $\mu \mathrm{L}$ RNAase (DNAase free), $3.0 \mu \mathrm{L}$ of human leucocytes (HLN)). The relative fluorescence of nuclei was measured using flow cytometry which was conducted in the immunology laboratory at King Khalid Hospital. The measurements of relative fluorescence intensity of nuclei stained with propidium iodide (PI) was performed on a linear scale and, typically, at least 10000 nuclei were analyzed for each sample. The histogram of relative DNA content was obtained after flow cytometric analysis of stained nuclei of soybean. Fresh HLN $(2 \mathrm{C}=7.0 \mathrm{pg})$ served as internal standards for PI flow cytometric analysis (Arumuganathan \& Earle, 1991). The analysis compared the mean position of the peaks of common bean nuclei with the mean peak position of the internal standard. Fluorescence ratios (2C DNA content/ sample, relative to the standard, were used to calculate DNA content (in picograms, pg) and the equivalent number of base pairs (genome size) was calculated assuming that $1 \mathrm{pg}$ DNA is equivalent to $0.965 \times 10^{9} \mathrm{bp}$ or $965 \mathrm{Mbp}$ according to (Dolezel et al., 2003) based on the following formula:

$$
2 \mathrm{C} \text { DNA content }(\mathrm{pg})=\frac{(\text { Sample Peak mean } \mathrm{x} \text { Standard DNA content }(7)}{\text { Standard Peak mean }}
$$

where the symbol (C) (the DNA content of the haploid set of chromosomes). 


\section{Single Cell Gel Electrophoresis assay (SCGE)}

\section{Isolation of nuclei and preparation of slides}

Nuclei were isolated from of untreated and treated common bean seeds using method of Juchimiuk, et al. (2006) as described in the study of Abdelhaliem and Al-Huqail (2016) by chopping seeds in a $60 \mathrm{~mm}$ petri dish with $0.2 \mathrm{~cm}^{3}$ of cold $400 \mathrm{mM}$ Tris-HCl buffer, $\mathrm{pH} 7.5$ (kept on ice), using a fresh sharp razor blade to release nuclei into the buffer under dim or yellow light. This method of isolating nuclei minimized DNA damage in the control cells. The resultant suspension of nuclei was used for the alkaline SCGE. Each slide previously coated with $1 \%$ normal melting point (NMP) agarose and dried, was covered with a mixture of $55 \mu \mathrm{L}$ nuclear suspension and $55 \mu \mathrm{L}$ low melting point (LMP) agarose (1\% prepared with phosphatebuffered saline) at $40^{\circ} \mathrm{C}$ and cover slipped. The slide was placed on ice for at least $5 \mathrm{~min}$, and the coverslip was removed. Then, $110 \mu \mathrm{L}$ LMP agarose $(0.5 \%)$ was placed on the slide and the coverslip was mounted. After 5 min on ice, the coverslip was removed.

\section{Measurement of nuclei diameters}

To measure of nuclei size, slides of SCGE with common bean nuclei imbedded in agarose were immersed in a horizontal gel electrophoresis tank containing freshly prepared icecold electrophoresis buffer ( $300 \mathrm{mM} \mathrm{NaOH}, 1 \mathrm{mM} \mathrm{Na} \mathrm{F}_{2}$ EDTA, $\left.\mathrm{pH}>13\right)$ and incubated for 15 min. Electrophoresis was performed at $16 \mathrm{~V}, 300 \mathrm{~mA}$, for $30 \mathrm{~min}$ at $4^{\circ} \mathrm{C}$. Next, the gels were neutralized by washing three times in $400 \mathrm{mM}$ Tris- $\mathrm{HCl}, \mathrm{pH} 7.5$ and stained with ethidium bromide $(20 \mu \mathrm{g} / \mathrm{mL})$ for $5 \mathrm{~min}$. After staining, the gels were dipped in ice-cold distilled water to remove excess of ethidium bromide and covered with a coverslip and immediately analyzed.

\section{Imaging and analysis software}

DNA-lesions in 50 randomLy selected nuclei per unwinding time on each slide were immediately analyzed and assessed qualitatively and quantitatively by visual scoring or the fluorescence microscope with an excitation filter of BP $546 / 10 \mathrm{~nm}$, a barrier filter of $590 \mathrm{~nm}$. A computerized CCD camera digital image analysis system (Komet Version 3.1, Kinetic Imaging Ltd, Liverpool, UK) was employed to measure the diameter of the nuclei. Tail moment (TM, integrated value of DNA density multiplied by migration distance) became a common descriptor along with tail length $(\mu \mathrm{m})$ and percentage of DNA in the tail, tail DNA (TD\%, relative percentage of DNA in the comet tail), were used as parameters of DNA damage.

\section{RAPD-PCR technique}

\section{Genomic DNA Isolation}

Genomic DNA was extracted from treated common bean seeds with MWCNTs, OTA and adsorbate OTA solutions in addition to qualitative and quantitative analyses of extracted DNA were carried out using the method described in the study of (Abdelhaliem and Al-Huqail, 2016). 


\section{RAPD-PCR analysis and agarose gel electrophoresis}

RAPD-PCR analysis and agarose gel electrophoresis were conducted described as in study of (Abdelhaliem and Al-Huqail, 2016). A total of 20 random DNA oligonucleotide primers (10 mer) were independently used for RAPD-PCR analysis (UBC, University of British Columbia, Canada) according to (Williams et al., 1990) with some modifications. Only four RAPD primers (P-03, 05, 06, and 10) succeeded to generate reproducible amplified DNA products. The PCR mixture contained $2.5 \mu \mathrm{L} 10 \mathrm{X}$ buffer with $15 \mathrm{mM} \mathrm{MgCl}_{2}$ (Fermentas, Vinius, Lithuania), with $0.25 \mathrm{mM}$ each dNTP (Sigma, St. Louis, MO, USA), $0.3 \mu \mathrm{M}$ primer, 0.5unit Taq DNA polymerase (Sigma), and 50 ng template DNA. PCR was performed in the Palm Cycler apparatus (Corbett Research) using the following profile: initial denaturation of $4 \mathrm{~min}$ at $95^{\circ} \mathrm{C}$ followed by 40 cycles of $1 \mathrm{~min}$ at $95^{\circ} \mathrm{C}, 1 \mathrm{~min}$ at $38^{\circ} \mathrm{C}$, and $2 \mathrm{~min}$ at $72^{\circ} \mathrm{C}$, with a final extension at $72^{\circ} \mathrm{C}$ for $10 \mathrm{~min}$ and a hold temperature of $4^{\circ} \mathrm{C}$ at the end.

\section{Agarose-gel electrophoresis of amplified gene products}

Products of amplification genes were electrophoresed on $1.5 \%(\mathrm{~m} / \mathrm{v})$ agarose gel (Sigma) in TAE buffer (0.04 M Tris-acetate, $1 \mathrm{Mm}$ EDTA, pH 8). The run was performed at 100-V constant voltage for $1 \mathrm{~h}$. A 100-bp DNA ladder (Gibco-BRL, Grand Island, NY, USA) was loaded into the first lane of each gel to evaluate the base pair length of DNA bands. The DNA bands were stained with $0.2 \mu \mathrm{g} / \mathrm{mL}$ ethidium bromide for $15 \mathrm{~min}$ and photographed under UV light using a gel documentation system (Bio-Rad, Hercules, CA, USA). After separating PCR products by agarose gel electrophoresis, gels were visualized with Photo Print (Vilber Lourmat, France) imaging system.

\section{RAPD profiles and analysis of data}

RAPD amplified bands were analyzed based on quantitative variations in the sizes of amplified DNA bands, their number, intensity as well as gain of new DNA bands or loss of normal ones were performed by Bio One D++ software (Vilber Lourmat, France). A binary matrix was made for determining the presence and absence of each amplified DNA bands (1 if present and 0 if absent) in each sample compared with control. Polymorphic DNA bands (unique and non-unique bands) and monomorphic bands were also scored. DNA polymorphisms generated by four primers were evaluated based on the appearance of a new band and the loss of a normal one compared with the control samples.

\section{Adsorption process and preparation of OTA adsorbate solutions}

\section{OTA adsorbate}

Three doses of ochratoxin A $(1.25,2.50,5.00 \mu \mathrm{g} / \mathrm{mL})$ prepared previously, prior to the adsorption process, were used for adsorption of OTA from their solutions onto MWCNT surface.

\section{MWCNTs adsorbent}

We tested the solid state $(50 \mu \mathrm{g})$ of improving and optimal MWCNTs dose $(50 \mu \mathrm{g} / \mathrm{mL})$ that exhibited significant enhancing of seed germination and seedling growth parameters and 
induced unexpected modifications of chloroplast and nuclei ultrastructure, was used as adsorbent for OTA onto its surface to alleviate the toxicity of OTA in the aqueous solutions of three OTA doses that used before adsorption process.

\section{Adsorption process}

The adsorption process was carried out as performed in the study of Yang and Xing (2009) with some modifications. Three replicates of solid state $(50 \mu \mathrm{g})$ MWCNTs was used as an adsorbent for each dose of OTA in separate Pyrex glass Erlenmeyer flasks $(250 \mathrm{~mL})$. The $\mathrm{pH}$ was adjusted in each flask to 6.0 before the addition of MWCNTs (Yang and Xing (2009). The $\mathrm{pH}$ of each OTA solution was controlled by $0.1 \mathrm{~mol} / \mathrm{L}$ sodium hydroxide $(\mathrm{NaOH})$ or hydrochloric acid $(\mathrm{HCl})$ at room temperature $\left(21-25^{\circ} \mathrm{C}\right)$. Samples were then stirred using a magnetic stirrer to mix for $24 \mathrm{~h}$. After that, the three flasks contained samples were shaken at $150 \mathrm{rpm}$ in a reciprocating shaker and kept in dark at $25 \pm 1{ }^{\circ} \mathrm{C}$ then, they were stirred in a VORTEX-Gene (mark) for $10 \mathrm{~min}$ and incubated for $2 \mathrm{~min}$ at room temperature and then centrifuged twice for $10 \mathrm{~min}$ at 14,000 rpm using a high-speed centrifuge (HermLe Z323, Germany) and the supernatant (the liquid phase) was collected after the end of absorption process and named 'OTA adsorbate solution'.

\section{Treatments $\boldsymbol{P}$. vulgaris seeds with three OTA adsorbate solutions after adsorption process}

The three liquid phases (supernatants) that named OTA adsorbate solutions were applied on common bean seeds as third treatments. Under the laboratory conditions, a completely randomized design with triplication was conducted to determine the effects of adsorbate OTA solutions on common bean seeds. Fresh, healthy uniformity size and surface sterilized common bean seeds ( 20 seeds) were placed in sterilized petri dishes and soaked in OTA adsorbate solutions separately for $48 \mathrm{~h}$. The treatment of OTA adsorbate solutions in addition to both treatments of MWCNTs and OTA were tested on $P$. vulgaris seeds at the same time alongside untreated seeds (control) and run at the same time in triplicate. The same bioassays and analyses used above for MWCNTs and OTA treatments were applied to the common bean seeds treated with three solutions of OTA adsorbate compared to that of the equivalent OTA doses before adsorption. This was carried out to estimate the extent of alterations and repairing of DNA that happened after adsorption process.

\section{Statistical analyses}

Each experiment in this study was carried out in triplicate. The data obtained were expressed as means \pm standard deviation (SD) and statistically analyzed by using one-way ANOVA. The P-value level was set at 0.05 .

\section{RESULTS}

\section{Characterization of MWCNTs}

The morphology of pure MWCNTs surface was observed typically under scanning electron microscope (SEM) as shown in Figure 2 (A) while Figure 2 (B 1-3) showed TEM images of dispersion of purified MWCNTs suspension in three MWCNTs doses (20,50, and 75 
$\mu \mathrm{g} / \mathrm{mL}$ ) used in this study at magnification power X200000. SEM morphological micrographs could be seen that the tubes were randomLy and loosely entangled together without any particlelike impurities. The MWNTs were observed to be 5 to $15 \mathrm{~nm}$ in thickness and 10-30 $\mu \mathrm{m}$ in length by dispersing the extremely diluted solution. TEM observation shows fine and homogeneous dispersion of MWNTs throughout the PA6 matrix. The variations in contrast and diameter of the MWCNTs are mainly according to dose.

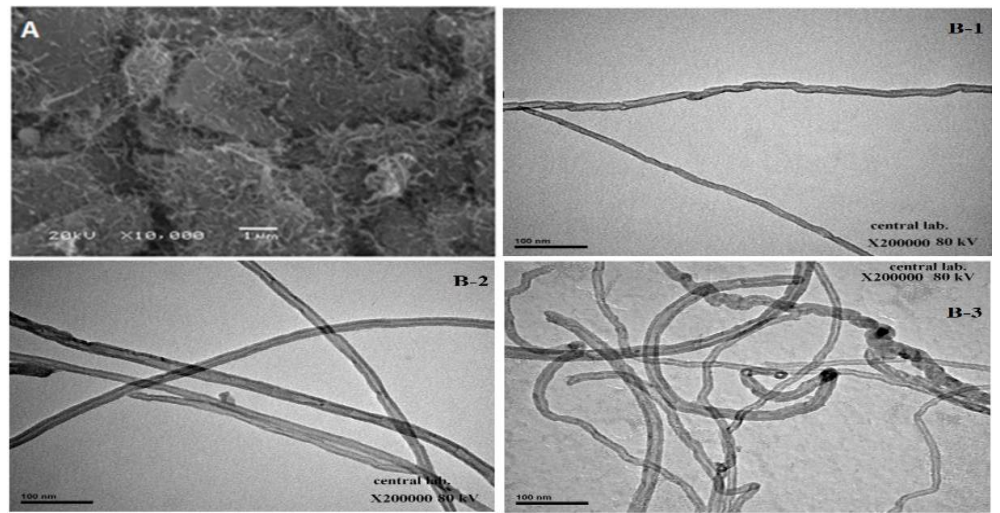

Figure 2. Macromorphological features of purified multi-wall carbon nanotubes (MWCNTs) under scanning electron microscopic (A) at magnification X10,000 and transmission electron microscopic (TEM) images of dispersion of purified MWCNTs suspension in three MWCNTs doses (B-1) $20 \mu \mathrm{g} / \mathrm{mL}$ (B-2) $50 \mu \mathrm{g} / \mathrm{mL}$, and (B-3) $75 \mu \mathrm{g} / \mathrm{mL}$ at magnification $\mathrm{X} 200,000$.

\section{Phenotypic parameters based on seed germination and seedling growth}

\section{Seed germination parameters}

Parameters of seed germination and seedling growth of untreated and treated common bean seeds following the three treatments (MWCNTs, OTA, and OTA adsorbate solutions) were estimated as shown in Table 2.

Three doses of MWCNTs induced variable actions ranging from significant energizing and enhancement of all parameters of seed germination and seedling growth especially at MWCNTs dose $(50 \mu \mathrm{g} / \mathrm{mL})$, which was superior to the untreated control in the inhibition and reduction of these parameters, especially at high MWCNTs doses $(75 \mu \mathrm{g} / \mathrm{mL})$, which was lower than the three OTA treatments Table 2. The final germination percent (FGP) significantly increased at the MWCNTs dose $(50 \mu \mathrm{g} / \mathrm{mL})$ reaching values of $(94.00 \pm 0.77,96.66 \pm 0.56$ and $105 \pm 0.33 \%$ ) after 48,72 and $96 \mathrm{~h}$ from emergence of radical respectively compared to the untreated control, which reached values of $(86.33 \pm 0.17,88.66 \pm 0.87$, and $93.60 \pm 0.77 \%$ respectively). On the other hand, phytotoxicity percentage of germinated seeds was in minus ($8.63 \pm 0.56 \%)$ at $50 \mu \mathrm{g} / \mathrm{mL}$ MWCNTs dose, which was under the 0.00 level of untreated sample. On the other hand, the low MWCNTs dose $(20 \mu \mathrm{g} / \mathrm{mL})$ gave minimum values of phytotoxicity $(2.10 \pm 1.45 \%)$, while a high MWCNTs dose $(75 \mu \mathrm{g} / \mathrm{mL})$ showed increasing phytotoxicity percentages over the untreated control, reaching values of $10.00 \pm 1.10 \%$.

On the other hand, three OTA doses showed diverse and toxic effects on seed germination parameters in a dose dependent manner compared with control and the MWCNTtreated seeds Table 2 . All seed germination parameters were significantly $(\mathrm{P}<0.05)$ decreased by the gradual increase of OTA dose. FGP reached maximum values of reduction $(16.60 \pm 0.87$, 
$16.66 \pm 0.47$, and $16.70 \pm 1.30 \%)$ at the higher OTA doses $(5 \mu \mathrm{g} / \mathrm{mL})$ after 48,72 and $96 \mathrm{~h}$ respectively. On the other hand, three OTA doses showed significant increases in phytotoxicity percentage with increasing OTA dose. The maximum percentage of phytotoxicity reached the value of $82.59 \pm 0.65 \%$ at a high OTA dose $(5 \mu \mathrm{g} / \mathrm{mL})$.

Following-up the results of this study, the effect of MWCNTs on OTA toxicity in common bean was investigated by comparing this toxicity before and after adsorption of OTA onto MWCNTs. Three OTA adsorbate solutions showed significant amelioration and improvement in all seed germination parameters of common bean compared with the equivalent OTA doses before adsorption process. However, the percentage of OTA phytotoxicity was substantially alleviated where reached the values of $(4.57 \pm 1.54 \%)$ at OTA adsorbate solution adsorbed from equivalent OTA dose $(1.25 \mu \mathrm{g} / \mathrm{mL})$ which scored phytotoxicity percentages reaching values of $61.85 \pm 0.74 \%$.

\section{Seedling growth parameters}

Seedling growth parameters after 40 days after planting untreated and treated common bean seeds with three treatments (MWCNTs, OTA, and OTA adsorbate solutions) were estimated (Table 2).

Seed viability or seed vigor determine the activity and behavior of the seed germination under the effect of different treatments that govern the capacity of seeds to express their vital functions. Each treatment showed specific effect on seedling vigor I and II. MWCNTs dose $(50 \mu \mathrm{g} / \mathrm{mL})$ showed a significant increase in vigor I and II indices over control which reached the values of (2716.00 and 280.00) for (VI) I and (VI) II respectively, compared to vigor indices values of untreated samples which reached (2325.58 and 232.28), respectively. On contrary, vigor indices decreased significantly at high OTA dose (5 $\mu \mathrm{g} / \mathrm{mL}$ ) which reached the values of (218.25 and 9.33) for (VI) I and (VI) II respectively (Table 2).

After adsorption process, the values of vigor indices (VI) I and (VI) II were ameliorated and increased by three OTA adsorbate solutions rather than their values scored at three equivalent OTA doses before adsorption process based on dose-dependent. The maximum values of vigor indices (VI) I and II were 1974.92 and 189.16 respectively of $1.25 \mu \mathrm{g} / \mathrm{mL}$ OTA adsorbate solutions compared to their values of equivalent dose before adsorption (619.92 and 38.47 respectively). These indicate that the adsorbent efficiency of optimal MWCNT dose had ability for binding OTA toxicity from the solutions of three OTA doses based on dose dependent.

Tolerant index expresses the capacity of a plant to battle against any toxic stress. Plants which have higher tolerant index value are tolerant to toxicity, while plants with low index value show less resistance. Common bean seedlings were tested for their tolerance to three treatments of MWCNTs, OTA and OTA adsorbate solutions in comparison to untreated sample. Tolerance index recorded the highest value of $(110.30 \pm 1.06 \%)$ at MWCNTs dose $(50 \mu \mathrm{g} / \mathrm{mL})$ while the lowest value of $(50.72 \pm 0.62 \%)$ scored at higher dose of OTA $(5 \mu \mathrm{g} / \mathrm{mL})$ compared to that of untreated value which reached the value of $(100.00 \%)$. Meanwhile, values of tolerance index were ameliorated and increased by three OTA adsorbate solutions based on OTA dose dependent before adsorption. It reached the maximum value of $(95.71 \pm 1.09)$ at $1.25 \mu \mathrm{g} / \mathrm{mL}$ OTA adsorbate solution compared to its value of the equivalent dose before adsorption $(69.99 \pm 0.99)$ (Table 2). 
Phytotoxicity is defined as a delay of seed germination, inhibition of plant growth or any adverse effect on plants caused by specific substances (phytotoxins). The percentage of phytotoxicity of roots and shoots lengths was varied among different treatments. At the level of MWCNTs, the phytotoxicity percentages of roots and shoots lengths was in minus under the 0.00 level of untreated sample. It reached the values of $(-27.22 \pm 0.82 \%$ and $-17.57 \pm 0.45 \%$ respectively) at optimal MWCNTs dose $(50 \mu \mathrm{g} / \mathrm{mL})$ while the lower and higher doses of MWCNTs $(20 \mu \mathrm{g} / \mathrm{mL}$ and $75 \mu \mathrm{g} / \mathrm{mL}$ respectively) pre and post this dose showed gradually increasing in phytotoxicity percentages compared to untreated control that showed no toxicity. In contrary, the percentages of phytotoxicity of roots and shoots lengths were significantly increased with increasing OTA dose. The maximum phytotoxicity values of root and shoot lengths reached $(49.69 \pm 0.64 \%$ and $48.13 \pm 1.20 \%)$ respectively at the high OTA dose $(5$ $\mu \mathrm{g} / \mathrm{mL}$ ) (Table 2).

The most interestingly in this study, three OTA adsorbate solutions showed a significant reduction in phytotoxicity percentages of roots and shoots lengths compared to equivalent OTA doses before adsorption processes (Table 2). The maximum decreasing of percentages of phytotoxicity of root and shoot lengths reached the values of $(3.66 \pm 1.72 \%$ and $5.01 \pm 0.95 \%$ respectively) at the $1.25 \mu \mathrm{g} / \mathrm{mL}$ OTA adsorbate solution compared to phytotoxicity percentages its of the equivalent dose before adsorption $(33.33 \pm 0.78 \%$ and $36.65 \pm 0.87 \%$ respectively).

Table 2. Phenotypic parameters of seed germination and seedling growth of untreated and treated common bean seeds with multi-wall carbon nanotubes (MWCNTs), Ochratoxin A (OTA), OTA adsorbate treatments and adsorbate OTA solutions.

\begin{tabular}{|c|c|c|c|c|c|c|c|c|c|c|c|c|c|c|}
\hline \multirow{3}{*}{ 竎 } & \multirow{3}{*}{ 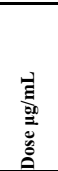 } & \multicolumn{6}{|c|}{ Seed germination parameters \pm SD } & \multicolumn{7}{|c|}{ Seedling growth Parameters \pm SD } \\
\hline & & \multicolumn{3}{|c|}{ Final germination percentages (FGP) } & \multirow{2}{*}{$\begin{array}{l}\text { Velocity } \\
\text { coefficient } \\
\text { of } \\
\text { germination } \\
\text { (CVG) }\end{array}$} & \multirow{2}{*}{$\begin{array}{l}\text { Means daily } \\
\text { germination } \\
\text { (MDG) }\end{array}$} & \multirow[b]{2}{*}{$\begin{array}{l}\text { Phytotoxicity } \\
\%\end{array}$} & \multirow{2}{*}{$\begin{array}{l}\text { Mean } \\
\text { Seedling } \\
\text { Lengths } \\
\text { (cm) }\end{array}$} & \multirow[b]{2}{*}{ Root Length } & \multirow[b]{2}{*}{ Shoot Length } & \multicolumn{2}{|c|}{$\begin{array}{l}\text { Vigor indices } \\
\text { (VI) of seedlings }\end{array}$} & \multirow{2}{*}{$\begin{array}{l}\text { Tolerance } \\
\text { index (TI) }\end{array}$} & \multirow{2}{*}{$\begin{array}{l}\text { Dry weight } \\
\text { of seedlings } \\
\text { (g) }\end{array}$} \\
\hline & & $48 \mathrm{~h}$ & $72 \mathrm{~h}$ & $96 \mathrm{~h}$ & & & & & & & $\begin{array}{l}\text { I } \\
\text { length }\end{array}$ & $\begin{array}{l}\text { II } \\
\text { weight }\end{array}$ & & \\
\hline \multirow[t]{2}{*}{ Control } & 0.00 & $86.33 \pm 0.17$ & $88.66 \pm 0.87$ & $93.60 \pm 0.77$ & $9.05 \pm 0.57$ & $24.16 \pm 1.40$ & 00.00 & $24.83 \pm 1.52$ & 00.00 & 00.00 & 2325.58 & 232.28 & $98.20 \pm 1.30$ & $2.48 \pm 0.02$ \\
\hline & 0.00 & $90.33 \pm 0.88$ & $93.33 \pm 1.77$ & $96.66 \pm 0.50$ & $9.77 \pm 0.47$ & $24.33 \pm 0.44$ & $2.10 \pm 1.45$ & $25.59 \pm 1.08$ & $1.80 \pm 1.47$ & $3.87 \pm 1.30$ & 2473.52 & 260.98 & $100 \pm 0.00$ & $2.70 \pm 0.04$ \\
\hline \multirow{3}{*}{ MWCNTs } & 50.00 & $94.66^{*} \pm 0.77$ & $96.66 \pm 0.56$ & $105.00^{*} \pm 0.33$ & $10.22 \pm 0.19$ & $26.45 \pm 0.09$ & $-8.63 \pm 0.56^{*}$ & $31.16 \pm 1.00$ & $-27.22^{*} \pm 0.82$ & $-17.57^{*} \pm 0.45$ & 2716.00 & 280.00 & $110.30 \pm 1.06$ & $2.80^{*} \pm 0.10$ \\
\hline & 75.00 & $82.00 \pm 0.87$ & $82.36^{*} \pm 0.19$ & $82.66^{*} \pm 0.34$ & $8.32^{z} \pm 0.14$ & $21.66^{*} \pm 1.02$ & $10.00^{*} \pm 1.10$ & $24.23 \pm 1.73$ & $2.69 \pm 1.38$ & $7.13 \pm 1.29$ & 2099.77 & 188.05 & $93.85 \pm 2.21$ & $2.17^{*} \pm 0.03$ \\
\hline & 1.25 & $36.66^{*} \pm 1.07$ & $36.66^{*} \pm 1.78$ & $36.66^{*} \pm 1.33$ & $3.97^{*} \pm 0.62$ & $9.16^{*} \pm 0.22$ & $61.85^{*} \pm 0.74$ & $16.91 \pm 1.51$ & $33.33 \pm 0.78$ & $36.65 \pm 0.87$ & 619.92 & 38.47 & $69.99^{*} \pm 0.99$ & $0.74^{*} \pm 0.02$ \\
\hline \multirow[t]{2}{*}{ OTA } & 2.50 & $26.60^{*} \pm 2.57$ & $26.66^{*} \pm 0.77$ & $26.66^{*} \pm 0.77$ & $2.88^{*} \pm 0.62$ & $6.66^{*} \pm 1.04$ & $72.22^{*} \pm 0.69$ & $14.40 \pm 1.30$ & $45.73 \pm 1.33$ & $42.19 \pm 1.05$ & 383.95 & 20.79 & $55.40^{*} \pm 1.83$ & $0.78^{*} \pm 0.02$ \\
\hline & 5.00 & $16.60^{*} \pm 0.87$ & $16.66^{*} \pm 0.47$ & $16.70^{*} \pm 1.30$ & $1.80 * \pm 0.62$ & $4.16^{*} \pm 0.32$ & $82.59^{*} \pm 0.65$ & $13.10 \pm 1.00$ & $49.69 \pm 0.64$ & $48.13 \pm 1.20$ & 218.25 & 9.33 & $50.72^{*} \pm 0.62$ & $0.58^{*} \pm 0.01$ \\
\hline \multirow{3}{*}{$\begin{array}{l}\text { OTA } \\
\text { sorbate } \\
\text { solutions }\end{array}$} & 1.25 & $82.15^{*} \pm 1.58$ & $84.70^{*} \pm 1.07$ & $89.32^{*} \pm 0.37$ & $7.96^{\circ} \pm 0.56$ & $20.83^{*} \pm 1.20$ & $4.57^{*} \pm 1.54$ & $22.50 \pm 1.59$ & $3.66 \pm 1.72$ & $5.01 \pm 0.95$ & 1974.92 & 189.16 & $95.71 \pm 1.09$ & $2.28^{*} \pm 0.20$ \\
\hline & 2.50 & $77.33^{*} \pm 0.77$ & $80.13^{*} \pm 0.70$ & $82.36^{*} \pm 0.34$ & $6.61^{*} \pm 0.62$ & $18.33^{*} \pm 0.43$ & $11.17^{*} \pm 0.55$ & $20.53 \pm 1.15$ & $13.14 \pm 1.00$ & $19.72 \pm 1.10$ & 1860.93 & 152.66 & $89.85^{*} \pm 1.47$ & $2.00^{*} \pm 0.60$ \\
\hline & 5.00 & $70.66^{*} \pm 1.45$ & $72.60^{*} \pm 0.13$ & $76.66^{*} \pm 1.03$ & $6.05^{*} \pm 0.81$ & $16.66^{*} \pm 1.44$ & $21.89^{*} \pm 0.89$ & $19.06 \pm 1.50$ & $22.58 \pm 1.03$ & $25.39 \pm 1.24$ & 1437.20 & 102.66 & $80.57^{*} \pm 0.17$ & $1.28^{*} \pm 0.10$ \\
\hline
\end{tabular}

\section{Ultrastructure modifications of chloroplasts and nuclei of common bean under Transmission Electron microscope (TEM)}

Ultrastructure of chloroplasts and nuclei of $P$. vulgaris treated with three MWCNTs doses $(20,50$, and $75 \mu \mathrm{g} / \mathrm{mL})$, three OTA doses $(1.25,2.50,5.00 \mu \mathrm{g} / \mathrm{mL})$, and three OTA adsorbate solutions alongside control were examined under TEM as shown in Figures (3-6) respectively, to assess and better understand the process of their ultrastructural changes induced by each treatment.

\section{Ultrastructure of untreated chloroplasts and nuclei of common bean}

Figure (3A) shows that untreated chloroplast had a typical ultrastructure with a cupshaped and elongated chloroplast containing a well- regular arrangement of grana stacks and a 
well-developed system of intergranal membranes (granum and stroma thylakoids) arranged along the main axis of the organelle as well as the presence of large number of clear electron starch granules and the absence of osmiophilic plastoglobuli (globular lipid droplets). On the other hand, untreated nuclei were more clearly and showed a typical organization with a welldeveloped double nuclear envelope, pronounced nucleolus and regular distribution of euchromatin and small patches of heterochromatin throughout the nucleoplasm Figure (3B).

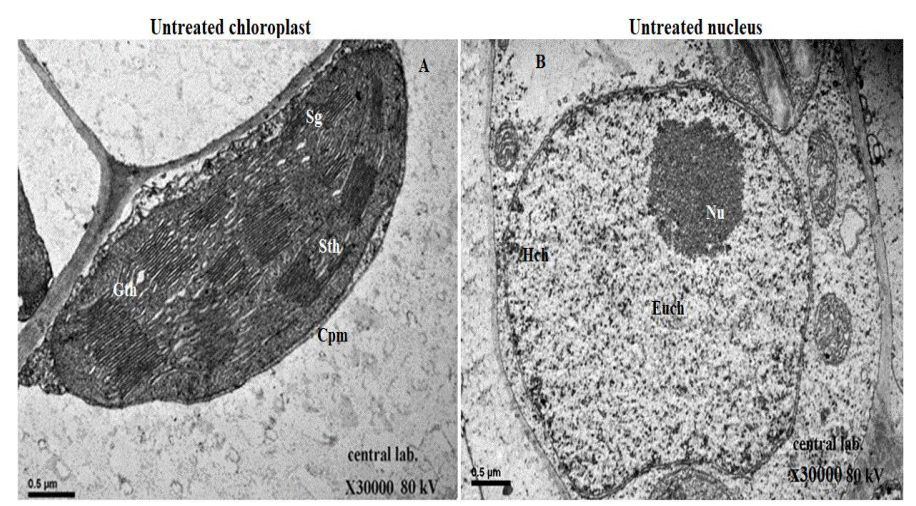

Figure 3. Electron micrographs of untreated $P$. vulgaris at magnification powers X30000. A: Chloroplast, its labels refers to; Cpm: Double membrane of chloroplast, Gth: Granal thylakoids, Sth: Stromal thylakoids, and Sg: starch grain and B: Nucleus, its labels refers to; Nm: Nuclear double membrane, Nu: nucleolus, Euch: Euchromatin, and Hch: Heterochromatin.

\section{Ultrastructure modification of Chloroplasts and nuclei treated with MWCNT doses}

The result obtained showed that three MWCNTs doses had variable actions on chloroplasts and nuclei ultrastructure of common bean as shown by TEM ranged from positive (improving) at MWCNT dose $(50 \mu \mathrm{g} / \mathrm{mL})$ to negative (toxic) changes at lower dose $(20 \mu \mathrm{g} / \mathrm{mL}$ ) and higher MWCNT dose $(75 \mu \mathrm{g} / \mathrm{mL})$ based on dose dependent Figures 4A-C.

The treated chloroplasts and nuclei with the low MWCNT dose $(20 \mu \mathrm{g} / \mathrm{mL})$ showed differences in their ultrastructure compared to untreated chloroplast and treated with MWCNT dose $(50 \mu \mathrm{g} / \mathrm{mL})$. At this dose, MWCNT were distributed obviously outside and inside of chloroplast membrane. The chloroplast at the low dose had elongated shaped at magnifications power X30000 compared to the untreated chloroplast. Some of its granal thylakoids showed a regular arrangement of grana stacks while others granal and stroma thylakoids were merged or lyses. There was one large plastoglobuli while nuclei were slightly irregular round shaped with destructed nuclear membrane at many regions in membrane and were smaller at magnifications power X60000 than untreated nuclei Figure 4A.

MWCNT dose $(50 \mu \mathrm{g} / \mathrm{mL})$ showed an unexpected vigorous change in size, external shape and internal structure of common bean chloroplasts. The chloroplasts treated with this dose were huge, elongated, more regular in arrangement of grana stacks (granum and stroma thylakoids), and very longer than the untreated chloroplasts that was small at the same magnifications power X30000 Figure 4B. Meanwhile, the threated nuclei with MWCNT dose $(50 \mu \mathrm{g} / \mathrm{mL})$ were bigger in size, round shaped with a well double nuclear membrane, and large, regular, rounded, acentric, and darkly nucleolus that was more obviously than untreated one at the same magnifications power X30000. Dispersed euchromatin and darkly patches of heterochromatin were regular distributed throughout the nucleoplasm as shown in Figure 4B. 
Furthermore, the treated chloroplasts and nuclei with high MWCNT dose $(75 \mu \mathrm{g} / \mathrm{mL})$ showed significant changes in the internal structure compared to untreated chloroplasts and other two MWCNTs doses at the same magnifications power X30000. At the high dose, MWCNTs were pronounced accumulated outside and inside membranes of chloroplast and nuclei leading to swollen chloroplasts with irregular ellipsoidal shaped with degradation or lyses of granal and stroma thylakoids as well as the presence of numerous large plastoglobuli and few starch granules inside stroma matrix while nuclei showed rounded shaped with deformation and degradation of most nuclear membrane, very small degraded nucleolus, and condensed and uncondensed chromatin distributed throughout nucleoplasm Figure 4C.

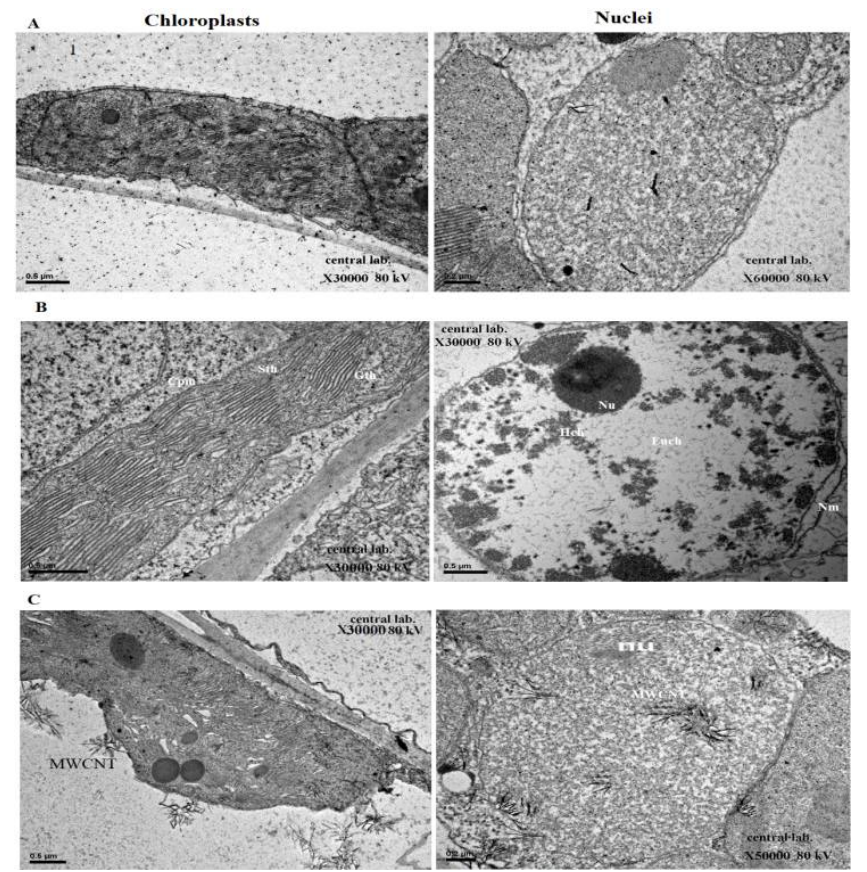

Figure 4. Electron micrographs of $P$. vulgaris chloroplasts and nuclei treated with three multi-wall carbon nanotubes (MWCNTs) doses A: $20 \mu \mathrm{g} / \mathrm{mL}, \mathrm{B}: 50 \mu \mathrm{g} / \mathrm{mL}$, and C: $75 \mu \mathrm{g} / \mathrm{mL}$ at magnification powers X30000 for chloroplasts and X60000, X30000, and X50000 for nuclei, respectively.

\section{Ultrastructure modification of chloroplasts and nuclei treated with OTA doses}

In contrast, ultrastructure of chloroplasts and nuclei of $P$. vulgaris treated with three OTA doses $(1.25,2.50,5.00 \mu \mathrm{g} / \mathrm{mL})$ illustrated dramatic alterations under TEM compared to untreated ones and three MWCNT doses as shown in Figures 5A-C. The risk and adverse impact of OTA on chloroplasts and nuclei was dose-dependent and more pronounced at high dose.

The treated chloroplasts with OTA dose $(1.25 \mu \mathrm{g} / \mathrm{mL})$ showed fusiform shaped with swelling of granal and stromal thylakoids. They contained numerous large plastoglobuli filling stroma matrix as well as accumulation of some starch grains. Grana stacks and intergranal membranes were as a network and not well differentiated while nuclei affected with this dose was small at magnifications power X60000 compared to untreated one that magnified at power X30000 and had organized rounded shape with deformed nuclear membrane and remained degraded nucleolus and condensed chromatin Figure 5A. 
On the other hand, the treated chloroplasts and nuclei with OTA dose $(2.50 \mu \mathrm{g} / \mathrm{mL})$ showed great differences from untreated ones. The chloroplasts had irregular elongated shape with many swollen thylakoids, and undulating membranes and intra-thylakoids spaces. There was accumulation of numerous starch grains differentially in sizes and numerous large plastoglobuli filling stroma matrix of chloroplast. Some of accumulated starch grains were vacuolated. Meanwhile, nuclei affected with this dose were deformed ellipsoidal shaped and smaller in size at magnifications power X80000 compared to untreated one that magnified at power X30000 as well as these nuclei had deformed and destructed nuclear membrane and lysed nucleolus and condensed heterochromatin filling the nucleoplasm Figure 5B.

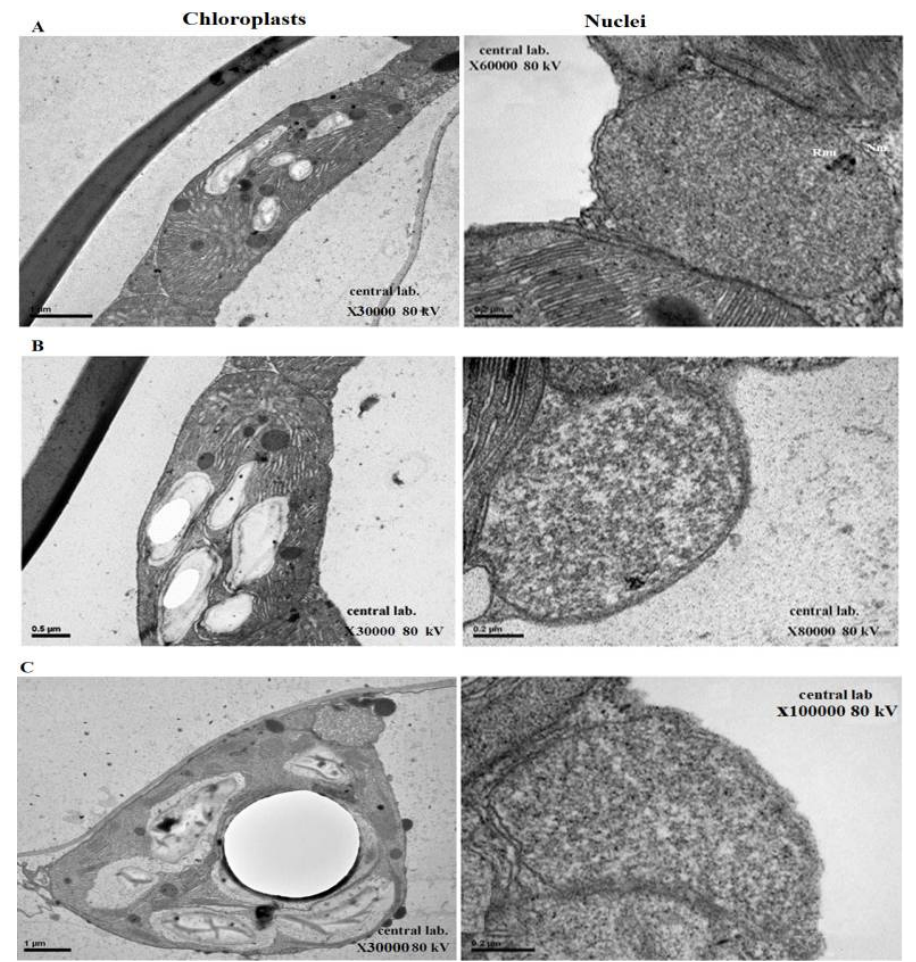

Figure 5. Electron micrographs of Phaseolus vulgaris chloroplasts and nuclei treated with ochratoxin A (OTA) doses A: $1.25 \mu \mathrm{g} / \mathrm{mL}$, B: $2.50 \mu \mathrm{g} / \mathrm{mL}$, and C: $5 \mu \mathrm{g} / \mathrm{mL}$ at magnification powers X30000 for chloroplasts and $\mathrm{X} 60000, \mathrm{X} 80000$, and X100000 for nuclei, respectively.

Furthermore, the high OTA dose $(5.00 \mu \mathrm{g} / \mathrm{mL})$ showed toxic and major adverse impact on chloroplasts and nuclei ultrastructure compared to untreated ones. The chloroplasts were swollen and irregular ellipsoidal shaped with poorly developed thylakoid membrane system. There were large accumulations of numerous starch grains, some of them showed large vacuolation with the presence of numerous large plastoglobuli on outer and intergranal membranes that filling stroma matrix while nuclei showed completely deformation, destruction and degradation of various components of nucleus such as nuclear membrane, nucleolus and chromatin material as well as the presence electron-dark particles filling nucleoplasm. Nuclei were very small in size at magnifications power X100000 compared to the untreated nucleus that magnified at power X30000 as in Figure 5C. 


\section{Ultrastructure modification of chloroplasts and nuclei treated with adsorbate OTA solutions}

The most interesting in this study, TEM illustrated obviously repair and amelioration in ultrastructure of chloroplasts and nuclei of $P$. vulgaris treated with OTA adsorbate solutions compared to treated chloroplasts and nuclei with the equivalent OTA doses prior adsorption process (Figure 6A-C). The chloroplasts and nuclei treated with $1.25 \mu \mathrm{g} / \mathrm{mL}$ OTA adsorbate showed clearest amelioration and repair of the viability of chloroplast and nuclei compared with treated seeds with the same dose before adsorption process (Figure 6A). Chloroplasts had ellipsoidal shaped with differentiated granum and stromal thylakoids filling most of the chloroplast with few and very small plastoglobuli distributed in stroma matrix as well as numerous starch grains. At the same time, treated nuclei with $1.25 \mu \mathrm{g} / \mathrm{mL}$ OTA adsorbate showed organized shape with peripheral nucleolus and double nuclear membranes. Dispersed and condensed chromatin material was also observed (Figure 6A).

On the other hand, the treated chloroplasts with $2.5 \mu \mathrm{g} / \mathrm{mL}$ adsorbate OTA solution were elongated in shape with few plastoglobuli. Most granum and stromal thylakoids were organized while few of them were merged. Meanwhile, nuclei treated with this adsorbate solution showed considerable improvement comparing to nuclei treated with the equivalent OTA dose before adsorption. These nuclei were irregular in shape with pronounced nucleolus, slight degradation in nuclear membrane and regularly distribution of chromatin throughout nucleoplasm (Figure 6B).

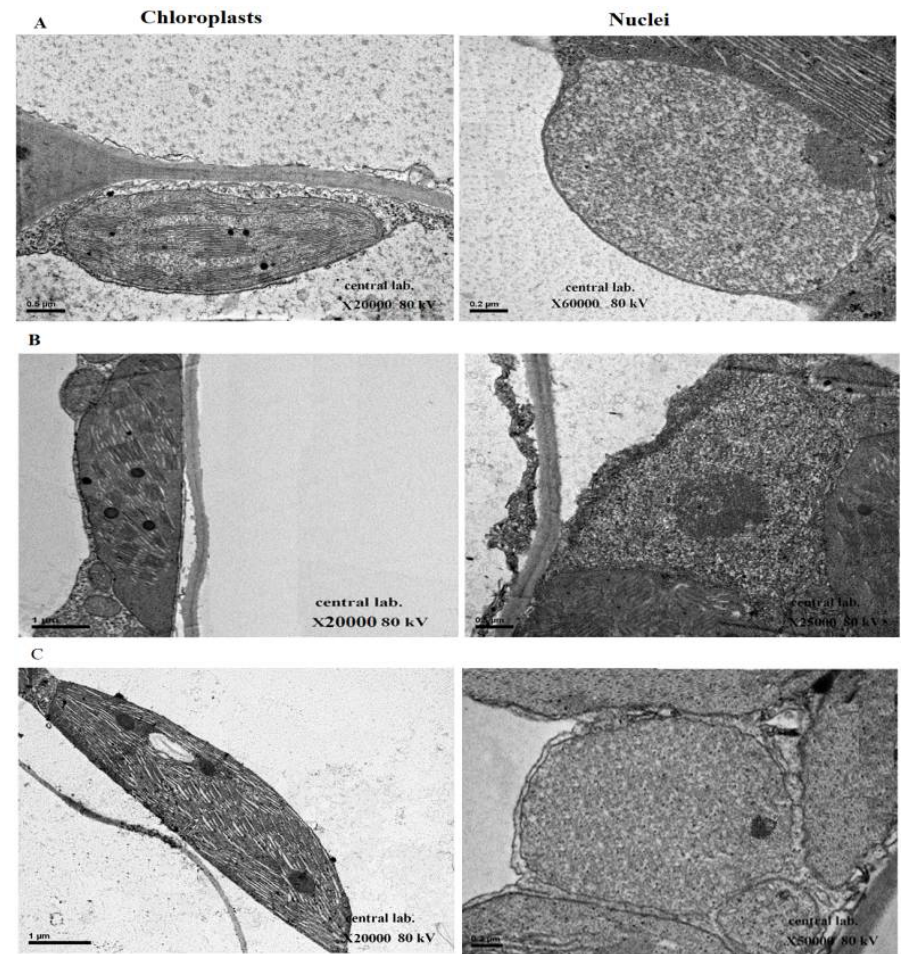

Figure 6. Electron micrographs of Phaseolus vulgaris chloroplasts and nuclei treated with ochratoxin A (OTA) adsorbate solutions from three OTA doses before adsorption A: $1.25 \mu \mathrm{g} / \mathrm{mL}, \mathrm{B}: 2.50 \mu \mathrm{g} / \mathrm{mL}$, and C: $5 \mu \mathrm{g} / \mathrm{mL}$ at magnification powers X20000 for all chloroplasts and X60000, X25000, and X50000 for nuclei, respectively. 
Furthermore, the treated chloroplasts with $5 \mu \mathrm{g} / \mathrm{mL}$ OTA adsorbate solution showed slightly amelioration comparing to treated chloroplast with the equivalent OTA dose before adsorption. They were fusiform shaped with double membrane and pronounced granal and stromal thylakoids. Stroma matrix had some large plastoglobuli and one accumulated starch granule while nuclei showed slight amelioration in their ultrastructure. These nuclei were irregular in shape with peripheral lysed nucleolus, destructed nuclear membrane at certain region, and condensed chromatin. Nucleus was small at magnifications power X50000 compared to the untreated nucleus (Figure 6C).

\section{DNA status based on flow cytometry technique}

The action of MWCNTs, OTA, and OTA adsorbate solutions alongside control were concentrated on common bean nuclei to evaluate the variations in nDNA content and genome size by flow cytometry in addition to genome size per the chromosome number of common bean (Table 3 and Figure 7).

Table 3. Nuclear DNA content and genome size of nuclei isolated from untreated and treated common bean seeds with multi-wall carbon nanotubes (MWCNTs), ochratoxin A (OTA), and OTA adsorbate solutions.

\begin{tabular}{|c|c|c|c|c|c|}
\hline Treatments & Dose $\mu g / m L$ & $\begin{array}{l}\text { Mean 2C nDNA } \\
\text { content (pg) }\end{array}$ & $\begin{array}{l}\text { 1C genome size } \\
\text { (Mbp) }\end{array}$ & Chromosome number & $\begin{array}{l}\text { Genome size/ } \\
\text { Chromosome number }\end{array}$ \\
\hline \multirow{2}{*}{ Control } & 0.00 & $8.19 \pm 0.006$ & 7903.35 & & 359.24 \\
\hline & 20 & $8.07 \pm 0.012$ & 7787.55 & & 353.98 \\
\hline \multirow{3}{*}{ MWCNTs } & 50 & $10.81 \pm 0.002$ & 10431.65 & & 474.17 \\
\hline & 75 & $7.86 \pm 0.005$ & 7584.9 & & 344.77 \\
\hline & 1.25 & $6.52 \pm 0.022$ & 6291.80 & $2 n=22$ & 285.99 \\
\hline \multirow[t]{2}{*}{ OTA } & 2.50 & $5.71 \pm 0.027$ & 5510.15 & & 250.46 \\
\hline & 5.00 & $4.14 \pm 0.055$ & 3995.10 & & 181.60 \\
\hline \multirow{3}{*}{$\begin{array}{l}\text { OTA adsorbate } \\
\text { solutions }\end{array}$} & 1.25 & $8.81 \pm 0.044$ & 8501.65 & & 386.44 \\
\hline & 2.50 & $8.23 \pm 0.073$ & 7941.95 & & 361.10 \\
\hline & 5.00 & $7.14 \pm 0.008$ & 6890.10 & & 313.19 \\
\hline
\end{tabular}

The obtained data showed an increase in nDNA content and genome size of common bean after being treated with MWCNT dose $(50 \mu \mathrm{g} / \mathrm{mL})$ which reached the value of $10.81 \pm 0.002 \mathrm{pg}$ and $10431.65 \mathrm{Mbp}$ respectively when compared to that of the nuclei isolated from untreated common bean seeds which reached the value of $(8.19 \pm 0.006 \mathrm{pg}$ and 7903.35 Mbp respectively). Meanwhile, the nuclear DNA content and genome size of the $20 \mu \mathrm{g} / \mathrm{mL}$ and $75 \mathrm{~g} / \mathrm{mL}$ doses decreased relative to the untreated (control) group that reached $8.07 \pm 0.012$ and $7.86 \pm 0.005$ pg for nDNA content respectively and 7787.55 and $7584.9 \mathrm{Mbp}$ for genome size respectively.

In contrary, the nuclei of the OTA-treated seeds showed a gradually decrease in nDNA content and genome size depending on dose. The maximum decrease in nDNA content and genome size scored at the $5 \mu \mathrm{g} / \mathrm{mL}$ which reached the values of $4.14 \pm 0.055 \mathrm{pg}$ and $3995.10 \mathrm{Mbp}$ compared to that of the untreated nuclei which reached $(8.19 \pm 0.006 \mathrm{pg}$ and 7903.35 Mbp respectively).

Furthermore, common bean nuclei treated with one of the three OTA adsorbate solutions showed improvement and amelioration in nDNA content and genome size values compared to equivalent OTA doses prior adsorption process. The most ameliorative doses 
showed an increase in nDNA content and genome size scored at OTA adsorbate from aqueous solution of 1.25 and $2.50 \mu \mathrm{g} / \mathrm{mL}$ doses reached the values of $8.81 \pm 0.044$ and 8.23 $\pm 0.073 \mathrm{pg}$ for nDNA content respectively and 8501.65 and $7941.95 \mathrm{Mbp}$ for genome size respectively, well over the value of that of the untreated nuclei of $8.19 \pm 0.006 \mathrm{pg}$ and 7903.35 Mbp respectively and in comparison to the values of nDNA content and genome size at the equivalent OTA doses used before adsorption which reached the values of $6.52 \pm$ 0.022 and $5.71 \pm 0.027 \mathrm{pg}$ for nDNA content respectively and 6291.80 and $5510.15 \mathrm{Mbp}$ for genome size respectively (Table 3 ).
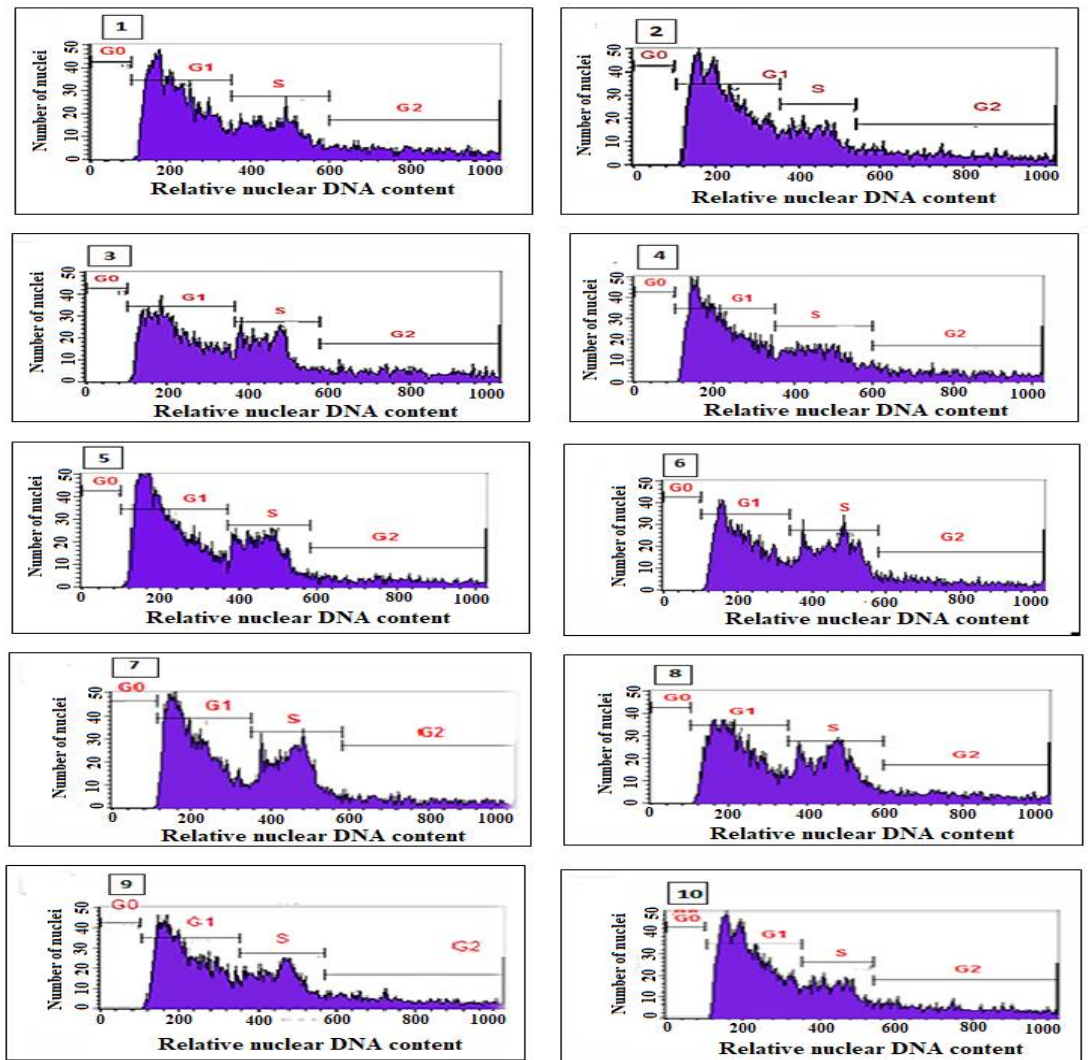

Figure 7. Flow cytometric analyses of nuclei isolated from untreated and treated common bean seeds which chopped and then stained with propidium iodide (1-10). $2 \mathrm{C}$ nDNA content (pg) estimated at $\mathrm{Gap}_{1}\left(\mathrm{G}_{1}\right)$ of interphase using peak position of the internal standard Human leucocytes (HLN) (2C nuclear DNA content 7.0 pg) as internal standard. (1) control, (2-4) multi-wall carbon nanotubes (MWCNTs) doses, (5-7) ochratoxin A (OTA) doses , and (8-10) OTA sorbate solutions, respectively.

\section{DNA status based on comet assay}

In the present study, the extent of DNA damage in treated common bean nuclei in response to MWCNTs, OTA doses and OTA adsorbate solutions alongside untreated one were estimated by the Comet assay (Single Cell Gel Electrophoresis) (Table 4) and Figure 8 (1-10) nuclear DNA (nDNA)-lesions with breaks migrate out of the nuclei in the electric field towards the anode as a comet tail while the remaining nuclear region appears as the 
comet head, resulting in a characteristic comet-like profile. The extent of comet-like profile indicates the level of nDNA damage in cells based on comet parameters, including Tail moment (TM) (integrated value of DNA density multiplied by migration distance) along with tail length $(\mu \mathrm{m})$ and higher percentage of tailed DNA (TD\%) (relative percentage of DNA in the comet tail) were used as parameters of DNA damage.

Table 4. Extent of nuclear DNA damage generated by comet assay in untreated and treated common bean nuclei with multi-wall carbon nanotubes, ochratoxin A, and OTA adsorbate.

\begin{tabular}{lcclllc}
\hline Treatment & $\begin{array}{l}\text { Dose } \\
\boldsymbol{\mu g} / \mathbf{m L}\end{array}$ & Tailed \% & Un-tailed \% & Tail length $(\boldsymbol{\mu m})$ & Tail DNA \% & Tail Moment Unit \\
\hline Control & 0.00 & 4 & 96 & 2.06 & 2.05 & 4.02 \\
MWCNTs & 20.00 & 6 & 94 & 3.56 & 3.74 & 6.42 \\
& 50.00 & 2 & 98 & 0.67 & 0.70 & 1.38 \\
OTA & 75.00 & 12 & 88 & 4.12 & 4.11 & 12.93 \\
& 1.25 & 13 & 87 & 4.05 & 4.16 & 16.85 \\
Adsorbate OTA solutions & 2.50 & 15 & 85 & 4.19 & 5.26 & 25.61 \\
& 5.00 & 19 & 81 & 5.31 & 3.52 & 6.36 \\
& 1.25 & 5 & 95 & 3.02 & 3.77 & 7.71 \\
\end{tabular}
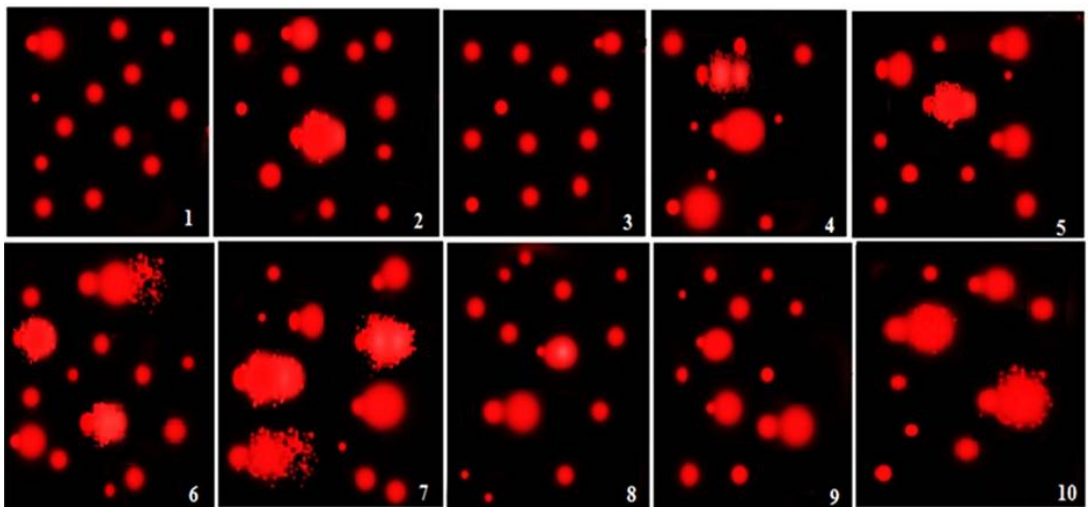

Figure 8. Comet images prepared by single cell gel electrophoresis (SCGE) show the variable extent of nuclear DNA damage in treated and untreated common bean nuclei. The images 1-10 represent (1) control, (2-4) multiwall carbon nanotubes (MWCNTs) doses, (5-7) ochratoxin A (OTA) doses, and (8-10) OTA adsorbate solutions, respectively.

Distinctive variations in the extent of nDNA damage of treated $P$. vulgaris were observed in this study; these variations reflecting specific interference of each treatment with nDNA. At the level of MWCNTs, $50 \mu \mathrm{g} / \mathrm{mL}$ improving MWCNTs dose (optimal) scored the minimum DNA migration and lowest DNA lesions based on DNA damage parameters (Tailed ratio $2 \%$ ) with tail length of $0.67 \mu \mathrm{m}$, TD\% of 0.70 , and TM of 1.38 compared to untreated sample, which recorded tailed ratio (4\%), tail length $(2.06 \mu \mathrm{m})$, TD\% (2.05), and TM (4.02) (Table 4) and Figure 8 (2). Meanwhile, the nDNA damage and DNA migration increased gradually at $20 \mu \mathrm{g} / \mathrm{mL}$ and $75 \mu \mathrm{g} / \mathrm{mL}$ MWCNTs doses compared to the untreated (control) group Table 4 and Figure 8 ( 3 and 4 respectively). On the contrary, increasing DNA damages and the maximum DNA migration (tailed ratio 19\%) with tail length $(5.31 \mu \mathrm{m}), \mathrm{TD} \%(5.41)$, and TM of 25.61 were remarkably evident at higher OTA 
dose $(5 \mu \mathrm{g} / \mathrm{mL})$ compared to untreated nuclei and nuclei treated with MWCNTs doses (Table 4) and Figure 8 (5-7).

OTA adsorbate solutions illustrated repair and amelioration of DNA as evident in decreasing DNA migration and damage based on equivalent OTA doses used before adsorption process (Table 4$)$ and Figure $8(8-10)$. Tailed ratio $(6 \%)$, tail length $(3.56 \mu \mathrm{m})$, TD\% (3.74), and TM (6.42) were scored at $1.25 \mu \mathrm{g} / \mathrm{mL}$ OTA adsorbate solution compared to these parameters at the same dose before adsorption process which scored tailed ratio (13\%), tail length $(4.05 \mu \mathrm{m}), \mathrm{TD} \%$ (4.16), and TM (6.42). This indicating that optimal MWCNT dose has good ability for binding OTA toxicity from their solutions leading to alleviation of OTA toxicity in common bean plant.

\section{DNA status based on RAPD-PCR technique}

This study estimated the extent of variations and damages in DNA of treated common bean seeds with MWCNTs, OTA doses and OTA adsorbate solutions in comparison to untreated DNA using RAPD-PCR (Tables 5, and Figure 9). It gave satisfactory results with many quantitative and qualitative alterations in the amplified DNA banding pattern of RAPD profiles. These alterations based on changes in number of amplified DNA products, sizes of banding DNA (bp), intensity of bands, fractionation of some bands, appearance of new bands (unique bands) and disappearance of some bands (polymorphic bands). Twenty random decamer primers were used for the RAPD analysis, only four 10-bp random RAPD primers (P-03, P-05, P-06, and P-10) with 60-70\% GC content succeeded to generate clear reproducible DNA bands.

RAPD analysis revealed 403 reproducible DNA bands with an average of 100.75 bands/primer. A reproducible set of DNA bands with variable number and DNA sizes were specific for each primer on gel electrophoresis, DNA sizes ranging from 154 to $1100 \mathrm{bp}$ in untreated and treated samples. Of these, 176 amplified DNA bands, with a value of $43.67 \%$ were polymorphic bands, out of which 58 unique DNA bands with a value of 14.39\%; 118 non-unique bands with a value of $29.28 \%$ as well as 3 monomorphic bands with a value of $0.74 \%$; two monomorphic bands generated by primer-06 and one generated by primer- 10 . Monomorphic DNA bands appeared at the same loci with the same molecular size in all treatments, and in untreated sample, although they differed in band intensity. Therefore, these two primers (P-06 and P-10) generated DNA polymorphism values of $95.74 \%$ and 97.62\% respectively because of the presence of monomorphic DNA bands while other primers (P-03 and P-05) generated 100\% DNA polymorphisms. Moreover, RAPD analysis generated total DNA polymorphism values of $98.32 \%$ based on the loss DNA bands from control sample and/or appearance of new DNA bands. Primer-06 produced the maximum number of amplified gene products at 110 bands, with a value of $27.30 \%$, while primer- 05 produced the minimum number of amplified gene products at 84 bands, with a value of $20.74 \%$.

Furthermore, the maximum number of amplified gene products generated by four primers was 55, with a value of $13.65 \%$ observed at samples treated with MWCNTs dose ( $50 \mu \mathrm{g} / \mathrm{mL}$ ) compared to 41 bands, with a value $10.17 \%$ for the control. This indicating the gain 14 new bands at this dose differing from control. On other hand, the minimum number of amplified gene products was 25 , with a value of $6.20 \%$ at samples treated with higher 
OTA dose $(5 \mu \mathrm{g} / \mathrm{mL})$. This indicating that loss 16 DNA bands at this dose differing from control.

On the other hand, three OTA adsorbate solutions showed increasing in the number of amplified DNA bands rather than three equivalent OTA doses used before adsorption and also rather than untreated samples. They reached 51, 47, and 43 DNA bands with values of $12.65,11.66,10.67 \%$ at $1.25,2.50,5 \mu \mathrm{g} / \mathrm{mL}$ OTA adsorbate solutions respectively.

Table 5. RAPD-PCR amplification products of genomic DNA extracted from untreated and treated Phaseolus vulgaris seed with multi-wall carbon nanotubes (MWCNTs), ochratoxin A (OTA) and OTA adsorbate solutions using the Bio-One D++ software (Vilber Lourmat, France). Lane (1) control, Lanes (24) three MWCNTs doses, Lanes (5-7) three OTA doses, and Lanes (8-10) three OTA adsorbate.

\begin{tabular}{|c|c|c|c|c|c|c|c|c|c|c|c|c|c|c|c|c|c|c|c|c|c|c|c|}
\hline \multirow{3}{*}{ 。ัّ } & \multirow{3}{*}{$\begin{array}{l}\text { Primers } \\
\text { sequences } \\
\left(5^{\prime} \rightarrow 3^{\prime}\right)\end{array}$} & \multirow{3}{*}{$\begin{array}{l}\text { Amplicon } \\
\text { lengths } \\
\text { (bp) }\end{array}$} & \multirow{3}{*}{ 预 } & \multicolumn{9}{|c|}{ Total number of scorable bands in each lane } & \multirow{3}{*}{$\begin{array}{l}\text { Total } \\
\text { bands } \\
\text { No } \\
\end{array}$} & \multirow{3}{*}{$\%$} & \multicolumn{6}{|c|}{ Polymorphic- bands } & \multirow{2}{*}{\multicolumn{2}{|c|}{$\begin{array}{l}\text { Monomorphic } \\
\text { bands }\end{array}$}} & \multirow{3}{*}{$\begin{array}{l}\% \text { of } \\
\text { Polymorphism }\end{array}$} \\
\hline & & & & ֻัฒ & $\dddot{\mathfrak{U}}$ & ت્d & 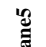 & ֻ & $\widehat{\varrho}$ & $\stackrel{\varrho}{\rightleftarrows}$ & ڤे & $\stackrel{ }{\Xi}$ & & & $\begin{array}{l}\text { Uni } \\
\text { (U) }\end{array}$ & & Non & & Tota & & & & \\
\hline & & & & & & & & & & & & & & & No & $\%$ & No & $\%$ & No & $\%$ & No & $\%$ & \\
\hline $\begin{array}{l}\mathrm{P}- \\
03\end{array}$ & $\begin{array}{l}\text { GTC } \\
\text { GCC } \\
\text { GTC A }\end{array}$ & $1100-175$ & 13 & 11 & 14 & 7 & 9 & 7 & 5 & 14 & 13 & 12 & 105 & 26.05 & 17 & 16.19 & 33 & 31.43 & 50 & 47.62 & 0 & 0 & 100 \\
\hline $\begin{array}{l}\mathrm{P}- \\
05\end{array}$ & $\begin{array}{l}\text { TGA } \\
\text { GCG } \\
\text { GAC A }\end{array}$ & $951-154$ & 8 & 10 & 11 & 6 & 8 & 7 & 5 & 11 & 10 & 8 & 84 & 20.74 & 11 & 13.10 & 29 & 34.52 & 40 & 47.62 & 0 & 0 & 100 \\
\hline $\begin{array}{l}\text { P- } \\
06\end{array}$ & $\begin{array}{l}\text { ACC } \\
\text { TGA } \\
\text { ACG G }\end{array}$ & $1000-191$ & 9 & 7 & 15 & 10 & 10 & 9 & 8 & 15 & 14 & 13 & 110 & 27.30 & 16 & 14.55 & 29 & 26.36 & 45 & 40.91 & 2 & 1.82 & 95.74 \\
\hline $\begin{array}{l}\text { P- } \\
10\end{array}$ & $\begin{array}{l}\text { GGT } \\
\text { CTA } \\
\text { CAC C }\end{array}$ & 1050- 197 & 11 & 12 & 15 & 9 & 9 & 10 & 7 & 11 & 10 & 10 & 104 & 25.81 & 14 & 13.46 & 27 & 25.96 & 41 & 39.42 & 1 & 0.96 & 97.62 \\
\hline$\%$ of & $\begin{array}{r}\text { Overall } \\
\text { total bands ir }\end{array}$ & $\begin{array}{l}\text { total } \\
\text { each lane }\end{array}$ & 21 & 40 & $\begin{array}{r}55 \\
20 .\end{array}$ & $\begin{array}{l}35 \\
35\end{array}$ & $\begin{array}{l}36 \\
\infty 2\end{array}$ & $\begin{array}{l}33 \\
\infty \\
\infty\end{array}$ & $\begin{array}{l}25 \\
\dot{0}:\end{array}$ & $\begin{array}{l}51 \\
0 .\end{array}$ & $\begin{array}{r}47 \\
0\end{array}$ & $\begin{array}{l}43 \\
0 . r\end{array}$ & 403 & & 58 & 14.39 & 118 & 29.28 & 176 & 43.67 & 3 & 0.74 & 98.32 \\
\hline
\end{tabular}

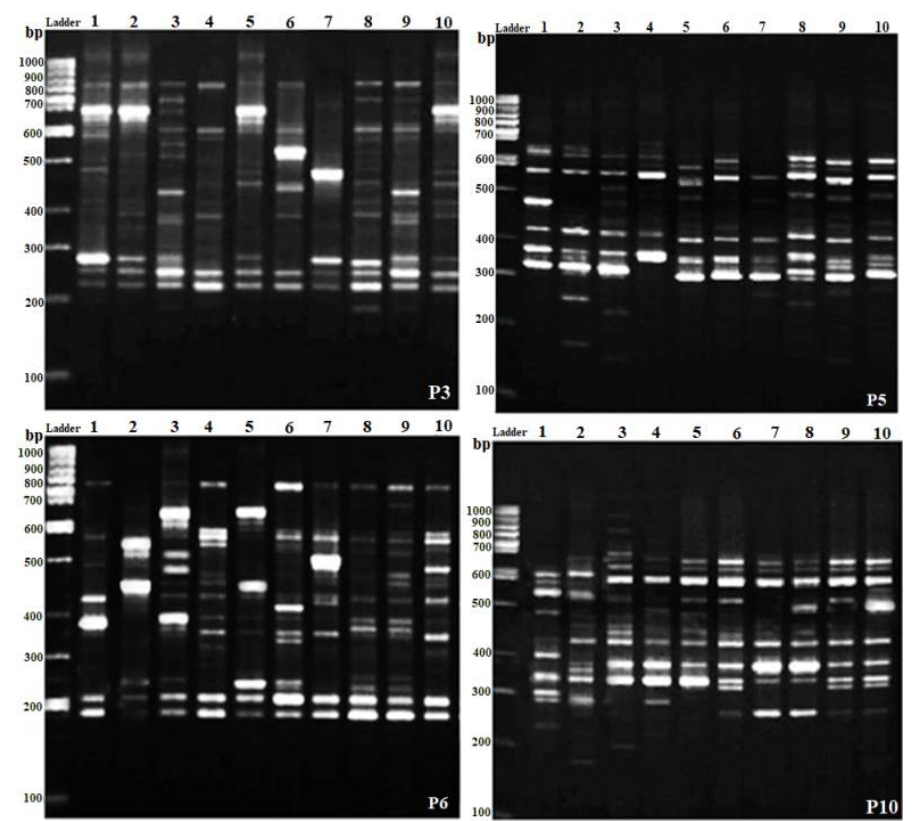

Figure 9. RAPD profiles of genomic DNA of common beans generated by four random decamer primers. The samples 1-10 represent control (1) multi-wall carbon nanotubes (MWCNTs) doses (2-4), ochratoxin A (OTA) doses (5-7), and adsorbate OTA solutions (8-10), respectively. 


\section{DISCUSSION}

The morphology of roots and shoots is extremely important for growth and development of all plants and any factor that changes their morphology has positive/negative effects on plants (Talebi, 2018). The results obtained in this study demonstrated that three treatments (MWCNTs, OTA, and OTA adsorbate solutions had highly variable actions on phenotypic, cellular ultrastructure and DNA status of common bean plant.

Data obtained in this study illustrated that three doses of MWCNTs showed specific and variable actions on phenotypic parameters of common bean plant, which may be due to doses or solubility of the applied MWCNTs and/or their possible dispersal and agglomeration in their suspension. These variable actions ranged from promoting to inhibitory action. Surprisingly, MWCNTs dose $(50 \mu \mathrm{g} / \mathrm{mL})$ was the best promoting dose (optimal dose). This was evident in its stimulatory action on seed germination and seedling growth of common bean over control (untreated sample) while gradual inhibitory actions recorded at low and was dramatically at high MWCNTs doses (20 and $75 \mu \mathrm{g} / \mathrm{mL}$ ), pre and post this optimal MWCNTs dose. In this respect, the study of Taleb (2018) showed that carbon nanoparticles at various doses have diverse effects on early growth of shoots, roots and seed germination while at the higher doses, they are poisonous for plants and inhibit their growth.

The improving action of optimal MWCNT dose $(50 \mu \mathrm{g} / \mathrm{mL})$ may be interpreted on the basis of its ability to penetrate the thick seed coat and positioned as micro-tubes creating new pores in seed coats which act as channels for enhancing water uptake, nutrients and oxygen inside seeds, a process by which it could stimulate seed germination and enhance seedling growth of common bean, these in accordance with (Tiwari et al., 2014).This may be confirmed that the presence of a correlation between the promoting action of MWCNT dose and its ability to the up-regulation and activation of marker genes that control the synthesis of water channel proteins (aquaporins) that essential for cell division, cell wall extension, plasma membrane formation, and improved and promotion of water uptake and transport (Martínez-Ballesta et al., 2016). Consistent with these reports, Khodakovskaya et al. (2013) observed that MWCNTs at certain concentrations can affect tomato plants phenotype positively and could grow bigger and faster compared to plants grown in control by increasing water uptake efficiency. So, the present study concluded that optimal MWCNT dose may consider as regulators and promotors dose for seed germination and seedling growth of common bean. in this respect, the study of Lahiani et al. (2018) supported our results where demonstrated that MWCNTs at dose $50 \mu \mathrm{g} / \mathrm{mL}$ showed no significant toxic effects on development of three important crop plants (barley, soybean, and corn) in addition to inducing several positive phenotypical changes and enhancement of photosynthesis due to improving the viability of chloroplasts.

On the other hand, at low and high MWCNT doses (20 and $75 \mu \mathrm{g} / \mathrm{mL})$, pre and post the optimal dose respectively induced perturbation and toxic actions on common bean seeds specially at high dose. The present study observed that good solubility and well dispersal of MWCNTs at low dose $(20 \mu \mathrm{g} / \mathrm{mL})$ may be led to speedily entrances into seeds and the diffusion faster across them causing seed imbibition damages, such as disturbed reconstitution of cell membranes, resulting in some toxicity that led to reducing seed germination and consequently slower the seedling growth of common bean. On the other 
hand, high MWCNT dose $(75 \mu \mathrm{g} / \mathrm{mL})$ showed potential toxic action of MWCNTs that may be dependent upon, dose and interaction with common bean plant that led to reducing the rate of seed germination and seedling growth. Toxicity mechanism of high MWCNTs doses may be interpreted on the base their accumulation on external surfaces of seeds preventing water uptake and decreasing the seeds proliferation and consequently lead to cell wall thickening by the attachment of MWCNTs to the proteins and polysaccharides of plant cell walls, decreasing of cell viability and damaging of the plasma membrane causing adversely effect on seed germination and seedling growth, this in accordance with the study of Martínez-Ballesta et al. (2016). Additionally, one of the prime increasing phytotoxicity of MWCNTs at high doses in common bean germinated seeds, they may be interact with the cell walls firstly due to their accumulation on external surfaces of seeds that may affect water and solute transport into seeds and after entering the cells, they may cause damages of membranes, macromolecules, and cellular organelles because of their ability to induction of cellular oxidative stress which induced as a result of overproduction and accumulation of harmful reactive oxygen species (ROS) and reduction the antioxidative defense system that lead to possibly attacking DNA, proteins, and membranes and resulting in cellular organelles injury during seed germination and early seedling growth (Zaytseva and Neumann, 2016).

On contrary, common bean seeds treated with three doses of ochratoxin A (OTA) showed significant dramatically toxic actions on common bean seeds based on reduction or inhibition of all parameters of seed germination and seedling growth depending on dose manner. This toxic action of OTA may be due to their ability in inhibition of antioxidant defense system of common plant and reduce the amounts of endogenous growth regulators that essential for seed germination and growth or inhibition of cell cycle progression by arresting cells at G2/M phase during somatic cell division leading to various damages in the entire genome (Ismaiel et al., 2015) or may be due to promotion of oxidative DNA damage through overproduction of harmful reactive oxygen species (ROS) generating covalent DNA adducts causing changes in physiological functions of cells and suppressing the enzymes required for seed germination and plant growth development (Pfohl-Leszkowicz and Manderville, 2012) In this respect, Lerda et al. (2010) investigated an inhibitory effect of OTA toxicity on root growth of Allium cepa at a concentration $(5 \mu \mathrm{g} / \mathrm{mL})$ associated with inhibition of proliferation activity.

The chloroplasts and nuclei were chosen to study the biochemical effects of applied treatments on common bean seedlings. In this study, major variability in ultrastructure of chloroplasts and nuclei were detected in plants exposed to MWCNTs, OTA, and OTA adsorbate solutions. Ultrastructural images obtained in this study revealed that chloroplast was the obvious and the most severely impacted organelle during toxic action of high doses of MWNTs and OTA treatments than nuclei.

The MWCNTs doses had variable actions on chloroplasts and nuclei ultrastructure of common bean ranged from positive (improving) to negative (toxic) changes as shown by TEM. Interestingly in this study, MWCNTs dose $(50 \mu \mathrm{g} / \mathrm{mL})$ was the best and optimal dose because of its ability to induce unexpected positive changes in chloroplasts and nuclei ultrastructure based on their giant sizes, unexpectedly well-developed system and welltypical organization of their ultrastructure that were better than untreated ones. The others MWCNT doses (20 and $75 \mu \mathrm{g} / \mathrm{mL}$ ) showed negative and gradual toxic impacts on 
chloroplasts and nuclei ultrastructure especially at high dose compared to control but their effects were lesser than the effect of OTA treatments.

The improving and positive action of optimal MWCNT dose $(50 \mu \mathrm{g} / \mathrm{mL})$ was explained on the basis that this dose may be increased antioxidant defense system of common bean plant and induced free radical-scavenging activities by suppressing the accumulation of superoxide- and hydroxyl radical that lead to improvement of structure and function of cellular organelles (Ghorbanpour and Hadian, 2015). Clear regular arrangement and well-developed system of intergranal and grana thylakoids of chloroplasts may be indicated the presence of all the pigment-protein complexes of the PS1 and 2 in thylakoids as the putative factors determining the structure and spatial orientation of the membrane system of chloroplasts (Lucchesini et al., 2006). On the other hand, negative (toxic) impacts of MWCNTs especially high dose $(75 \mu \mathrm{g} / \mathrm{mL})$ may be due to the accumulation of MWNTs on or in chloroplasts and nuclei leading to generation harmful reactive oxygen species (ROS) and decreasing cell proliferation causing alteration in common bean physiological processes, including increasing cellular oxidative stress and possibly attacking membranes, resulting in cellular injury and disruption of membrane integrity as well as deformation of shapes and structure of cellular organelles that reduce their viabilities (Zaytseva and Neumann, 2016).

On contrary, OTA treatments based on dose-dependent showed highly significant adverse toxic impact on ultrastructure of common bean chloroplast and nuclei compared to untreated and MWCNTs treatments. The high dose OTA exhibited major toxic action and clear deformation of chloroplast and nuclei ultrastructure ranged from distortion in external and internal structure to disruption of membrane integrity that consider as distinctive mark of cell death as well as obviously decreasing in their sizes, bursting of envelopes, degradation of thylakoid membranes, swelling of thylakoid lamellae, and their expansion, induction of the osmiophilic droplets (Plastoglobuli), accumulation of starch grains in addition to eventual shrinkage of the nucleus destruction of their membranes and dissolution of their components. These highly toxic action of OTA may be due to their ability to induction high production of reactive oxygen species (ROS) which are highly reactive and toxic resulting in oxidative stress and causing serious damage for cellular components of chloroplast and nuclei (Pfohl-Leszkowicz and Manderville, 2012).

Any agent is considered genotoxic if it can cause an adverse effect on DNA lead to lesions in its structure and/or function. The current study showed remarkable variations in the extent of DNA damage experience by the nuclei of common bean treated with MWCNTs, OTA. Each treatment used showed specific interaction with nuclear DNA based on dose dependent manner. the data obtained in this study illustrated that OTA treatments resulted in an obvious genotoxic action led to reduction in nuclear DNA content and genome size and induction an increase in migration and damage of common bean DNA when comparison to that of the untreated samples and MWCNTs treatments prior and post adsorption process.

The increasing or reduction of nuclear DNA content and genome size due to applied treatments may be induced by certain mutations causing random changes in the nuclear DNA including gene, chromosomal or genomic mutations and hence, creating variability in nDNA content which is directly related to the genome sizes (Abdelhaliem and Al-Shalawi, 2019). These mutations may be due to the addition of a number of chromosomes or chromosomal segments or the duplication of genetic material or addition (insertion) of new 
nitrogenous base pairs into genetic pool nucleus or chromosomes that led to increasing in the diameter of inflorescence and consequently nDNA content as observed at MWCNTs dose $(50 \mu \mathrm{g} / \mathrm{mL})$ or may be due to a reduction in chromosome number or deletion of genetic material or segments of chromosomes that led to reduced nDNA content as observed at the other two MWCNTs (20 and $75 \mu \mathrm{g} / \mathrm{mL}$ ) and three doses of OTA treatments (Monteiro et al., 2010).

On the other hand, Pfohl-Leszkowicz and Manderville (2012) proved that genotoxicity by OTA may stem from its oxidative metabolism into electrophiles that are capable of reacting covalently with DNA to generate covalent DNA adducts and consequently cytotoxicity, cell cycle effects, and inhibition of DNA synthesis due to producing free radicals oxygen (ROS) through a direct and/or indirect effect to induce lesions and DNA breaks in the irradiated cells leading to the reduction of nDNA contents. So, flow cytometry has been used successfully to assess increased dispersion that results from DNA or chromosomal damages.

The present study critically compared the validity of the Comet assay and FCM in evaluating molecular cytogenetic toxicity in $P$. vulgaris cells and demonstrated that the data provided by both techniques complement each other and presented high correlation levels in detection of the degree of genotoxicity and DNA lesions induced in common bean cells.

Single cell gel electrophoresis (comet assay) is one of the most advanced techniques for the detection of DNA damage and repair at the level of most eukaryotic cells especially crop plants. The data obtained in the current study showed that each treatment used showed specific interaction with nuclear DNA damages based on their ability to induction of oxidative stress (ROS) which plays an important role in identifying treatment with its genotoxic activity. The higher genotoxic activity will lead to higher level DNA damage.

The current study observed that the lowest percentage of tail DNA (TD\%) and tail moments (TM) showed by optimal MWCNTs dose $(50 \mu \mathrm{g} / \mathrm{mL})$ may be due to its ability to penetrate seed coat of common bean seeds and increasing the water content inside them by enhancing water uptake leading to improvement the levels of antioxidant defense system in common bean cells which result in reducing high levels of ROS by inducing the production of free radical-scavenging activities that protect DNA and minimize DNA lesions of common bean and its ability to suppress accumulation of superoxide- and hydroxyl radicalinitiated lipid peroxidation induced DNA damages (Ghorbanpour and Hadian, 2015).

On the other hand, toxic action of MWCNTs pre and post this optimal dose scored extents of nDNA lesions that were higher at high dose compared to nDNA of control. nDNA lesions induced by the toxic action of these treatments may be due to their ability to generate reactive oxygen species (ROS) based on dose dependent and exerted oxidative stress on common bean DNA leading to altering DNA bases and causing oxidative DNA damage. MWCNTs-induced DNA base modification at higher doses may also cause subsequent breakdown of the DNA double strand producing DNA damages and can interact with proteins and DNA and alter their native structures (Zaytseva and Neumann, 2016). The high doses of MWCNTs induced more oxidative lesions and caused more DNA damage in Allium cepa DNA as detected by comet assay (Ghosh et al., 2015).

Furthermore, toxic action OTA treatment induced variable extents of DNA lesions based on dose dependent which were obviously highest at higher OTA dose. These DNA lesions detected by comet assay may be the primary target of oxidative stress induced by OTA treatments and provide information about the DNA damages caused by high toxicity 
of OTA. A wide range in appearances of the comets induced by toxic action of OTA indicated that some nuclei may be contained large numbers of strand breaks damaged DNA (negatively charged forms tail). The increase in tail moment detected by comet assay due to toxic action of OTA based on dose dependent may be due to direct induction of DNA strand breaks and/or indirect (oxidative DNA damage) by generation of structural modifications in DNA induced by reactive oxygen species (ROS) that produce excessive damage to the cellular DNA forming a DNA-reactive quinone and guanine-specific DNA adducts that provide an important source of mutation leading to DNA damages (Pfohl-Leszkowicz and Manderville, 2012 ). These DNA lesions caused increased DNA migration and lost higher extents of DNA as comets. The present results indicate that common bean cells have a very sensitive cellular response to the mycotoxin, OTA, at the highest dose $(5 \mu \mathrm{g} / \mathrm{mL})$ that caused toxicity and genetic injury leading to damage plant DNA indirectly, this is in accordance with Lerda et al. (2010) who indicated that OTA could induce damage at the DNA level of Allium cepa at the same OTA dose $(5 \mu \mathrm{g} / \mathrm{mL})$.

RandomLy amplified polymorphic DNA-polymerase chain reaction (RAPD-PCR) technique used in this study as an indicator of DNA changes and DNA lesions following the exposures to MWCNT, OTA, and adsorbate OTA solutions. Detection of RAPD profile variations and extent of DNA damages induced by toxic actions of some doses of these treatments involved the comparison between control (untreated) and treated samples and between treated samples with each other.

The study observed that each treatment recorded a specific level of alterations in amplified DNA profiles of $P$. vulgaris based on the variations in amplified DNA size, number of amplified DNA products, DNA intensity as well as loss of normal bands or gain of new amplified DNA bands. These variations might be due to the structural rearrangements in DNA caused by different types of DNA damages. The maximum number of amplified gene products generated by four random RAPD primers was 55 generated by optimal MWCNTs dose $(50 \mu \mathrm{g} / \mathrm{mL})$, suggesting that it probably caused mutations at the genomic level such as large addition of nitrogenous bases or insertion of the newly amplified DNA regions. This newly DNA bands increased the number of DNA products at the related dose of treatments may be due to ability of this dose to affect expression of a number of genes like those expressed for aquaporins proteins that are involved in promotion of water uptake and transport necessary for cellular metabolic processes (Martínez-Ballesta et al., 2016).

On the other hand, variations in amplified DNA sizes generated by RAPD-PCR technique may be interpreted as separate loci which are scored based on amplification and non-amplification of DNA segments by PCR, depending on positions that are complementary to the primers' sequence (Kekec et al., 2010). The current study observed variations in the DNA banding pattern generated by RAPD analysis could be interpreted based on the biological manner by toxic action of high doses of MWCNT and three doses of OTA treatments may be due to interaction with DNA producing ROS in affected cells through direct and/or indirect effects causing changes within base pair sequences of DNA between binding oligonucleotide priming sites, such as chromosomal rearrangement, rearrangements of the genomic DNA strand breaks, base pair deletions or insertion of nitrogenous base sequences, pyrimidine dimers, cross-links and base modifications as well as mutations including inversions, translocations, and transpositions or may be due to the interactions of Taq polymerase with damaged DNA (Atienzar et al., 2006). These variations 
resulting in appearance (gain) or disappearance (loss) of DNA bands and consequently, high levels of DNA polymorphisms.

The gain of new DNA bands resulting from mutation when they occur at the same locus in a sufficient number of cells such as insertions or addition of the amplified DNA bands and transpositions of some genes due to the effect of some treatments (Atienzar et al., 2006) while loss of some DNA bands (polymorphic bands) may be related to large deletions of amplified DNA regions or breaks in double-strand of DNA molecule that lead to loss of the DNA band between the breaks or a single base change in the genomic DNA may prevent amplification by introducing a mismatch at just one end of this segment DNA segment leading to losing this segment (Atienzar et al., 2006).

The high levels of DNA polymorphisms generated by RAPD may be reflection of structural changes in the genomic DNA that alter the distance between two annealing sites and delete an existing site of new one or reflection of variation in gene expression which would be a better parameter to measure the pattern of DNA damages induced by toxic stress of some treatments (Atienzar et al., 2006).Thus, DNA fingerprinting revealed by RAPDPCR offers a useful biomarker assay in detection of genetic actions of treatments used in this study.

The most interestingly in this study, application of adsorbate OTA solutions on common bean seeds showed a significant amelioration and improvement in all germination and growth parameters, increasing viability and tolerant of seeds against OTA toxicity led to reduction of phytotoxicity percentage, clearly improving of chloroplast and nuclei ultrastructure led to increasing their viability as well as alleviating their genotoxicity on common bean DNA that gave it resistance against lesions induced by genotoxic action of OTA as evident in increasing DNA contents and genome sizes and decreasing migration and damages of DNA and repairing largest extents of DNA lesions in addition to their abilities to renewed the appearance of new amplified DNA bands compared with treated seeds of equivalent three OTA doses used alone before adsorption process. This may be due to alleviation the levels of OTA toxicity in adsorbate solutions depending on OTA doses used before adsorption leading to inducing antioxidants defense system of them may be by reducing reactive oxygen species (ROS)-induced by OTA toxicity and increasing activities of free radical-scavenging that led to activating and a significant amelioration of the above mentioned parameters (Ghorbanpour and Hadian, 2015).

\section{CONCLUSIONS}

In conclusion, we demonstrated that MWCNTs induced variable actions on common bean seeds, ranging from improving actions especially at the appropriate dose (50 $\mu \mathrm{g} / \mathrm{mL}$ ) to inhibitory actions at the other doses, especially at the highest MWCNTs dose. Thus, we suggest that an appropriate MWCNTs dose (optimal) should be used as effective MWCNTs -fertilizers for Eco-friendly farming.

No previous studies reported on the use of multiwalled carbon nanotubes as an adsorbent for alleviation or modulation the hazardous impact of OTA toxicity on plants. Data obtained from all bioassays (phenotypic parameters, transmission electron microscopy, flow cytometry, comet assay, and RAPD) indicated that the optimal MWCNTs dose (50 $\mu \mathrm{g})$ exhibited high adsorbent capacity for binding toxicity of OTA compared to the solutions of equivalent OTA doses used prior the adsorption process leading to modulation and 
alleviation of the levels of OTA toxicity and consequently improved all parameters of these bioassays. We suggest that additional studies should be conducted to confirm this hypothesis that an appropriate dose is necessary and to apply the adsorbent efficiency of MWCNT against different mycotoxins in the future as a "nanocarbon-mycotoxic product" for protection of crop plants and increasing their quality and yields.

\section{ACKNOWLEDGMENTS}

The authors would like to extend their sincere appreciation to King Abdul Aziz City for Science and Technology (KACST) and Research's Centre, Faculty of Science, King Saud University for supporting this work.

\section{CONFLICTS OF INTEREST}

The authors declare no conflict of interest.

\section{REFERENCES}

Abdelhaliem E and Al-Huqail AA (2016). Detection of protein and DNA damage induced by elevated carbon dioxide and ozone in Triticum aestivum L. using biomarker and comet assay. Genet. Mol. Res. 15 (2): GMR8736. Doi: $10.4238 / \mathrm{gmr} .15028736$.

Abdelhaliem E and Al-Shalawi J (2019). Attenuation of lead genotoxicity in Glycine max by adsorbent nanosized titanium dioxide using phenotypic, cytogenetic and DNA status bioassays. Genet. Mol. Res. 18(3): GMR18350. Doi: $10.4238 / \mathrm{gmr} 18350$.

Arumuganathan K and Earle ED (1991). Estimation of Nuclear DNA Content of Plants by Flow Cytometry. Plant Mol. Biol. Rep. 9(3): 208-218. Doi:10.1007/BF02672069.

Atienzar FA and Jha AN (2006). The random amplified polymorphic DNA (RAPD) assay and related techniques applied to genotoxicity and carcinogenesis studies: A critical review. Mutat. Res. 613: 76-102. Doi: 10.1016/j.mrrev.2006.06.001.

Dikilitas M, Kocyigit A and Ve Yigit F (2009). A molecular-based fast method to determine the extent of DNA damages in higher plants and fungi. Afr. J. Biotechnol. 8 (14): 3118-3127.

Dolezel J, Bartos J, Voglmayr H and Greilhuber J (2003). Nuclear DNA content and genome size of trout and human. Cytom. A. 51A (2): 127-128. Doi: 10.1002/cyto.a.10013.

El Khoury A and Atoui A (2010). Ochratoxin A: General Overview and Actual Molecular Status. Toxins (Basel). 2(4): 461-493. Doi: 10.3390/toxins2040461.

Fathi Z, Nejad RAK, Mahmoodzadeh H and Satari TN (2017). Investigating of a wide range of concentrations of multiwalled carbon nanotubes on germination and growth of castor seeds (Ricinus communis L.). JPPR. 57: 228-236. Doi: 10.1515/jppr-2017-0032.

Ghorbanpour M and Hadian J (2015). Multi-walled carbon nanotubes stimulate callus induction, secondary metabolites biosynthesis and antioxidant capacity in medicinal plant Satureja khuzestanica grown in vitro. Carbon. 94: 749759. Doi: 10.1016/j.carbon.2015.07.056.

Ghosh M, Bhadra S, Adegoke A, Bandyopadhyay M, et al. (2015). MWCNT uptake in Allium cepa root cells induces cytotoxic and genotoxic responses and results in DNA hyper-methylation. Mutat. Res. Genet. Toxicol. Environ. Mutagen. 774: 49-58. Doi: 10.1016/j.mrfmmm.2015.03.004.

Gopalakrishnan Nair PM (2018). Toxicological impact of carbon nanomaterials on plants. In: Gothandam K, Ranjan S, Dasgupta N, Ramalingam C, Lichtfouse E (eds) Nanotechnology, Food Security and Water Treatment. Environmental Chemistry for a Sustainable World. Springer, Cham. Doi: 10.1007/978-3-319-70166-0_5.

Horky P, Skalickova S, Baholet D and Skladanka J (2018). Nanoparticles as a solution for eliminating the risk of mycotoxins. Nanomaterials. 8: 727-247. Doi: 10.3390/nano8090727.

Ihsanullah HA, Asmaly TA, Saleh T, Laoui VK, et al. (2015). Enhanced adsorption of phenols from liquids by aluminum oxide/carbon nanotubes: comprehensive study from synthesis to surface properties. J. Mol. Liq. 206: 176-182. Doi: 10.1016/j.molliq.2015.02.028.

Ismaiel AA and Papenbrock J (2015). Mycotoxins: Producing Fungi and Mechanisms of Phytotoxicity Agriculture. 5: 492-537. Doi: 10.3390/agriculture5030492. 
Jang MH and Hwang YS (2018). Effects of functionalized multi-walled carbon nanotubes on toxicity and bioaccumulation of lead in Daphnia magna. PLoS one. 13(3): e0194935. Doi: 10.1371/journal.pone.0194935.

Jiang D, Wei D, Wang L, Ma S, et al. (2018). Multiwalled carbon nanotube for one-step cleanup of 21 mycotoxins in corn and wheat prior to ultraperformance liquid chromatography-tandem mass spectrometry analysis. Toxins. 10: E409. Doi: 10.3390/toxins10100409.

Juchimiuk J, Gnys A and Maluszynska J (2006). DNA damage induced by mutagens in plant and human cell nuclei in acellular comet assay. Folia Histochem. Cytobiol. 44: 127-131.

Kalavacharla VL, Liu Z, Meyers BC, Thimmapuram J, et al. (2011). Identification and analysis of common bean (Phaseolus vulgaris L.) transcriptomes by massively parallel pyrosequencing. BMC Plant Biol. 11: 135-152. Doi: 10.1186/1471-2229-11-135.

Kaphle A, Navya PN, Umapathi A, Chopra M, et al. (2017). Nanomaterial impact, toxicity and regulation in agriculture, food and environment. In: Ranjan S, et al. (eds) Nanoscience in food and agriculture 5. Sustainable agriculture reviews, vol 26. Springer International Publishing AG, Cham. pp 205-242. Doi: 10.1007/978-3-319-58496-6_8.

Kekec G, Sakcali MS and Uzonur I (2010). Assessment of genotoxic effects of boron on wheat (Triticum aestivum L.) and bean (Phaseolus vulgaris L.) by using RAPD analysis. Bull Environ Contam. Toxicol. 84(6): 759-764. Doi: 10.1007/s00128-010-0031-z.

Khodakovskaya MV, de Silva K, Biris AS, Dervishi E, et al. (2012). Carbon nanotubes induce growth enhancement of tobacco cells. ACS Nano. 6(3): 2128-2135. Doi: 10.1021/nn204643g.

Khodakovskaya MV, Kim BS, Kim JN, Alimohammadi M, et al. (2013). Carbon nanotubes as plant growth regulators: effects on tomato growth, reproductive system, and soil microbial community. Small. 9: 115-123. Doi: 10.1002/smL1.201201225.

Lahiani MH, Nima ZA, Villagarcia H, Biris AS, et al. (2018). Assessment of Effects of the Long-Term Exposure of Agricultural Crops to Carbon Nanotubes. J. Agric. Food Chem. 66: 6654-6662. Doi: 10.1021/acs.jafc.7b01863.

Lerda D, Biagi Bistoni M, Pelliccioni P and Litterio N (2010). Allium cepa as a biomonitor of ochratoxin A toxicity and genotoxicity. Plant Biol. (Stuttg). 12(4): 685-688.

Lucchesini M, Monteforti G, Mensuali-Sodi A and Serra G (2006). Leaf ultrastructure, photosynthetic rate and growth of myrtle plantlets under different in vitro culture conditions. Biol. Plant. 50: 161-168. Doi: 10.1007/s10535-006$0001-9$.

Ma X and Agarw S (2016). Review Adsorption of Emerging Ionizable Contaminants on Carbon Nanotubes: Advancements and Challenges. Molecules. 21: 628-639.

Madrigal-Santillán E, Morales-González JA, Vargas-Mendoza N, Reyes-Ramírez P, et al. (2010). Antigenotoxic Studies of Different Substances to Reduce the DNA Damage Induced by Aflatoxin B1 and Ochratoxin A. Toxins. 2(4): 738-757.

Martínez-Ballesta MC, Zapata L, Chalbi N and Carvajal M (2016). Multiwalled carbon nanotubes enter broccoli cells enhancing growth and water uptake of plants exposed to salinity. J. Nanobiotechno. 14: 42-55. Doi:10.1186/s12951-016-0199-4.

Mastronardi E, Tsae P, Zhang X, Monreal C, et al. (2015). Strategic role of nanotechnology in fertilizers: potential and limitations. In: Rai M, Ribeiro C, Mattoso L, Duran N (eds). Emerging nanotechnologies in Food and Agriculture. Verlag, New York, NY, pp. 25-68. Springer, Cham. Doi: 10.1007/978-3-319-14024-7_2.

Mishra A and Choudhuri MA (1999). Monitoring of phytotoxicity of lead and mercury from germination and early seedling growth indices in two rice cultivars. Water Air Soil Pollut. 114: 339-346. Doi: 10.1023/A:1005135629433.

Mohamed MA, Hashim AF, Alghuthaymi MA and Abd-Elsalam KA (2018). Nano-carbon: Plant Growth Promotion and Protection, Nanobiotechnology Applications in Plant Protection pp.155-188. Springer, Cham. Doi: 10.1007/978-3319-91161-8_7.

Monteiro MS, Rodriguez E, Loureiro J, Mann RM, et al. (2010). Flow cytometric assessment of Cd genotoxicity in three plants with different metal accumulation and detoxification capacities. Ecotoxicol. Environ. Saf. 73: 1231-1237. Doi: 10.1016/j.ecoenv.2010.06.020.

Pereira VL, Fernandes JO and Cunha SC (2014). Mycotoxins in cereals and related foodstuffs: A review on occurrence and recent methods of analysis. Trends Food Sci. Technol. 36: 96-136. Doi: 10.1016/j.tifs.2014.01.005.

Pfohl-Leszkowicz A and Manderville RA (2012). An update on direct genotoxicity as a molecular mechanism of ochratoxin a carcinogenicity. Chem. Res. Toxicol. 25(2): 252-262. Doi: 10.1021/tx200430f.

Puzyr AP, Purtov KV, Shenderova OA, Luo M, et al. (2007). The Adsorption of Aflatoxin B1 by Detonation-Synthesis. Dokl. Biochem. Biophys. 417: 299-301. Doi: 10.1134/s1607672907060026.

Sadegh H, Ali GAM, Gupta VK and Makhlouf SH (2017). The role of nanomaterials as effective adsorbents and their applications in wastewater treatment. J. Nanostruct. Chem. 7: 1-14. Doi: 10.1007/s40097-017-0219-4.

Santos CL, Pourrut BV and Ferreira de Oliveira JM (2015). The use of comet assay in plant toxicology: recent advances. Front Genet. 6: 216. Doi: 10.3389/fgene.2015.00216.

Schmidt R, Kunkowska AB and Schippers JHM (2016). Role of Reactive Oxygen Species during Cell Expansion in Leaves. Plant Physiol. 172(4): 2098-2106. Doi: 10.1104/pp.16.00426.

Sliwinska E (2006). Nuclear DNA content analysis of plant seeds by flow cytometry. Current Protocols in Cytometry. 35(1): 7.29.1-7.29.13. Doi: 10.1002/0471142956.cy0729s35. 
Sliwinska E, Zielinska E and Jedrzejczyk I (2005). Are seeds suitable for flow cytometric estimation of plant genome size? Cytometry Part. A. 64A: 72-79. Doi: 10.1002/cyto.a.20122.

Talebi SM (2018). Nanoparticle-Induced Morphological Responses of Roots and Shoots of Plants. Nanomaterials in Plants, Algae and Microorganisms. 1: 119-141. Doi: 10.1016/B978-0-12-811487-2.00006-2.

Tanveer A, Rehman A, Javaid MM, Abbas RN, et al. (2010). Allelopathic potential of Euphorbia helioscopia L. against wheat (Triticum aestivum L.), chickpea (Cicer arietinum L.) and lentic (Lens culinaris Medic.). Turk. J. Agric. 34: 75-81. Doi: 10.3906/tar-0903-53.

Tanveer A, Safdar ME, Tariq MA, Yasin M, et al. (2014). Allelopathic inhibition of germination and seedling vigor of some selected crops by Achyranthes aspera L. Herbologia. 14(2): 35-46. Doi: 10.5644/Herb.14.2.04.

Tiwari DK, Dasgupta-Schubert N, Villasenor Cendejas LM, Villegas J, et al. (2014). Interfacing carbon nanotubes (CNT) with plants: enhancement of growth, water and ionic nutrient uptake in maize (Zea mays) and implications for nanoagriculture. Appl. Nanosci. 4(5): 577-591. Doi: 10.1007/s13204-013-0236-7.

Vashisth A and Nagarajan S (2010). Effect on germination and early growth characteristics in sunflower (Helianthus annuus) seeds exposed to static magnetic field. J. Plant Physiol. 167: 149-156. Doi: 10.1016/j.jplph.2009.08.011.

Wang X, Han H, Liu X, Gu X, et al. (2012). Multi-walled carbon nanotubes can enhance root elongation of wheat (Triticum aestivum) plants. J. Nanopart. Res. 14: 841-850. Doi: 10.1007/s11051-012-0841-5.

Williams JGK, Kubelik AR, Livak KJ, Rafalski JA, et al. (1990). DNA polymorphisms amplified by arbitrary primers are useful as genetic markers. Nucleic Acids Res. 18: 6531-6535. Doi: 10.1093/nar/18.22.6531.

Yang J, Cao W and Rui Y (2017). Interactions between nanoparticles and plants: phytotoxicity and defense mechanisms. J. Plant. Interact. 12: 158-169. Doi: 10.1080/17429145.2017.1310944.

Yang k and Xing B (2009). Adsorption of fulvic acid by carbon nanotubes from water. Environ. Pollut. 157: 1095-1100. Doi: 10.1016/j.envpol.2008.11.007.

Zaytseva O and Neumann G (2016). Carbon nanomaterials: production, impact on plant development, agricultural and environmental applications. Chem. Biol. Technol. Agric. 3: 17-42. Doi: 10.1186/s40538-016-0070-8. 